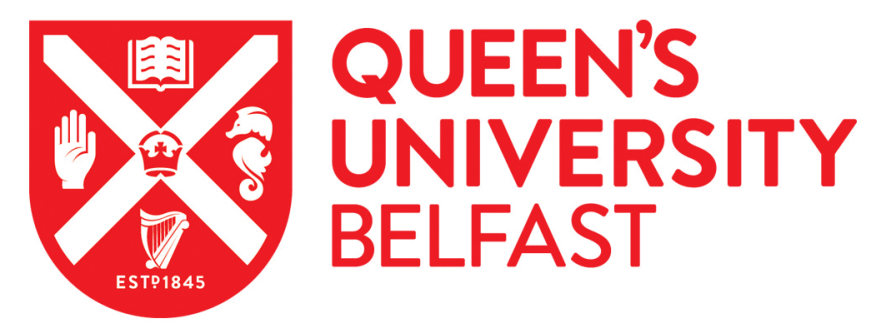

\title{
Characterisation of Large Disturbance Rotor Angle and Voltage Stability in Interconnected Power Networks with Distributed Wind Generation
}

Meegahapola, L., \& Littler, T. (2015). Characterisation of Large Disturbance Rotor Angle and Voltage Stability in Interconnected Power Networks with Distributed Wind Generation. IET Renewable Power Generation, 9(3), 272283. https://doi.org/10.1049/iet-rpg.2013.0406

Published in:

IET Renewable Power Generation

Document Version:

Peer reviewed version

Queen's University Belfast - Research Portal:

Link to publication record in Queen's University Belfast Research Portal

Publisher rights

Copyright The Institution of Engineering and Technology 2015.

This paper is a postprint of a paper submitted to and accepted for publication in IET Renewable Power Generation and is subject to Institution of Engineering and Technology Copyright. The copy of record is available at IET Digital Library.

\section{General rights}

Copyright for the publications made accessible via the Queen's University Belfast Research Portal is retained by the author(s) and / or other copyright owners and it is a condition of accessing these publications that users recognise and abide by the legal requirements associated with these rights.

\section{Take down policy}

The Research Portal is Queen's institutional repository that provides access to Queen's research output. Every effort has been made to ensure that content in the Research Portal does not infringe any person's rights, or applicable UK laws. If you discover content in the

Research Portal that you believe breaches copyright or violates any law, please contact openaccess@qub.ac.uk. 


\title{
Characterisation of Large Disturbance Rotor Angle and Voltage Stability in Interconnected Power Networks with Distributed Wind Generation
}

\author{
Lasantha Meegahapola1, Tim Littler² \\ ${ }^{1}$ School of Electrical, Computer and Telecommunications Engineering \\ University of Wollongong, Wollongong, 2500, Australia \\ ${ }^{2}$ The Queen's University of Belfast, School of Electronics, Electrical Engineering \\ and Computer Science, Belfast BT9 5AH, UK
}

\begin{abstract}
Wind generation in highly interconnected power networks creates local and centralised stability issues based on their proximity to conventional synchronous generators and load centres. This paper examines the large disturbance stability issues (i.e. rotor angle and voltage stability) in power networks with geographically distributed wind resources in the context of a number of dispatch scenarios based on profiles of historical wind generation for a real power network. Stability issues have been analysed using novel stability indices developed from dynamic characteristics of wind generation. The results of this study show that localised stability issues worsen when significant penetration of both conventional and wind generation is present due to their non-complementary characteristics. In contrast, network stability improves when either high penetration of wind and synchronous generation is present in the network. Therefore, network regions can be clustered into two distinct stability groups (i.e. superior stability and inferior stability regions). Network stability improves when a voltage control strategy is implemented at wind farms, however both stability clusters remain unchanged irrespective of change in the control strategy. Moreover, this study has shown that the enhanced fault ride-through (FRT) strategy for wind farms can improve both voltage and rotor angle stability locally, but only a marginal improvement is evident in neighbouring regions.
\end{abstract}

\section{Key Words}

Doubly-fed induction generator (DFIG), interconnected system, rotor angle stability, system inertia, voltage stability, wind generation. 


\section{Introduction}

Wind resource distribution is a significant determinant when characterising stability of an interconnected power network. This is due to the fact that operational and control techniques of wind generators can significantly influence system dynamics based on their proximity to conventional synchronous generation and load centres. A number of countries are planning for $100 \%$ renewables in their future power networks [1-2], and wind generation has been identified as a major contributor towards achieving these renewable energy targets. Power electronic based variable-speed wind generators (VSWGs) are dominant in the wind generation industry due to their superior active and reactive power controllability, less reactive power consumption and ability to meet grid-code standards [3-4]. However, VSWGs are inherently less responsive to system dynamics, since their mechanical dynamics are decoupled from the electrical dynamics by the power electronic converter system, and hence they are less responsive to frequency variations in the network [3-4]. In addition, plant response characteristics of various conventional generation technologies (e.g. combined-cycle gas turbine (CCGT)) will also influence on frequency stability [5].

A number of studies have been conducted on transient and voltage stability using actual power systems with significant penetration of wind generation (approximately $50 \%$ wind penetration based on total system load). The studies conducted by Akhmatov [6-7] analysed short-term voltage stability issues in the Danish power network with fixed-speed wind generators (FSWGs), doubly-fed induction generators (DFIGs), and combined heat and power (CHP) units. These studies illustrated that protective disconnection (due to low-voltage protection) of wind generators; in particular, the FSWGs can reduce the risk of voltage collapse in the system by reducing the reactive power demand following a fault in the network. These researchers have further advocated that the fault ride-through (FRT) capabilities of wind generators can reduce the risk of voltage collapse during a network fault. Moreover, those studies have shown that voltage stability can be improved by installing dynamic reactive power compensation at certain nodes in the network. The 
Spanish network study conducted by Rodriguez et al. [8] and Usala [9] examined voltage stability issues in the Spanish power system with FSWGs and DFIGs in the network. A comparison between both technologies showed that DFIGs have much better voltage stability performance than FSWGs. The Nordic system study conducted with the FSWG based wind generation has also analysed the dynamic voltage behaviour and stability during grid faults [10], and shown that the impact of FSWGs is local but may result in sustained power oscillations.

Stability studies presented in [11] argued that transient and voltage stability improved by high voltage network connection of wind farms, and a study on wind technology mixes has shown that optimal wind technology mix [12] can improve overall system stability by using complementary characteristics of different wind generators. Stability studies conducted based on variable-speed wind generation systems (i.e. DFIGs) are limited to simplified network structures, and few fault scenarios [13-14]. In [15] impact of wind integration approaches to transient stability has been presented. The impact of DFIG operating mode on transient stability [16-17] and voltage stability [18] has been investigated and concluded that voltage control mode is beneficial for stability. In [19] authors have advocated that DFIGs give rise to both beneficial and detrimental impact on stability due to change in inertia in the network.

This study is motivated from the All Island TSO Facilitation of Renewables Studies report [20], which has indicated that geographic distribution can be an influential factor for system stability. Therefore, it is imperative to characterise system stability with geographically distributed wind resources. Historical wind generation and load data from the Ireland power network were used to derive realistic wind and load distribution scenarios for the test system while utilising the scenario reduction technique presented in [21]. A unique set of stability indices were developed considering the characteristics of wind generation. This study presents a novel contribution towards characterising large disturbance rotor angle and voltage stability in highly interconnected system with geographically distributed wind resources while 
considering the dynamic characteristics of various plant models for conventional generators.

\section{Dynamic Models of the Test Network and DFIG}

\subsection{The New England 39 bus system}

The New England (NE) 39 bus system was reconfigured to replicate the generation portfolio and wind regions of a wind rich power network. Therefore, original network load and generation have been augmented to facilitate wind generation in the system, while the original network topology was kept unchanged. The governor droop was set at $4 \%$, and the exciters were represented by the standard IEEE models [22]. A schematic of the NE-39 bus system is illustrated in Figure 1.

In the modified NE-39 system, the maximum network load is $8,500 \mathrm{MW}$, while the total installed conventional generation capacity of the network is 9,910 MW. Each network area is installed with open-cycle gas turbines (OCGTs), since variability of wind resources require fast-start generation resources to cope up with the network demand during system operation. Nine wind farms are installed across five regions in the NE-39 system while creating wind rich and wind poor regions in the network. Each wind farm can generate $665 \mathrm{MW}$, and total installed wind capacity of the network is approximately 6,000 MW. The total wind capacity is comprised of DFIG, since the majority of onshore wind generators are of DFIG type, and it is expected to retain the same trend in future [4]. Wind generators are assumed to have reactive power capability of $+/-100$ MVAr, which is independent of active power dispatch of the generator unit. Wind generation was added to the network at the locations shown in Figure 1. The wind farm nodes were strategically chosen on the basis of proximity to system loads, and existing synchronous generation. An aggregated wind farm model has been used, and the configuration is similar to the topology used in [15]. The each wind generator was rated at $5 \mathrm{MW}$ and actual number of wind generators included in a wind farm was based on the required size of the wind farm. The generation capacities installed in each area of the NE-39 system are shown in Table 1. 
Table 1: Installed generation capacity of the NE-39 System

\begin{tabular}{c|c|c|c|c|c}
\hline \hline Area & CCGT (MW) & OCGT (MW) & ST (MW) & DFIG (MW) & Load (MW) \\
\hline 1 & 900 & 620 & 0 & 1334 & $1,553.4$ \\
\hline 2 & 1100 & 180 & 0 & 667 & 676.5 \\
\hline 3 & 2250 & 180 & 1350 & 2001 & 3,728 \\
\hline 4 & 900 & 350 & 0 & 667 & 939.8 \\
\hline 5 & 900 & 280 & 900 & 1334 & $1,602.4$ \\
\hline \hline
\end{tabular}

\subsection{The DFIG Dynamic Simulation Model}

A DFIG dynamic simulation model was developed in DIgSILENT Power Factory. Operation and control strategies were adapted from the existing commercial wind generator models [23-24]. The DFIG parameters are taken from [25]. The DFIG model was designed as a three-mass model (with turbine, drive-shaft and generator inertia) and the drive-train system was represented with finite shaft-stiffness. Since the simulation time is limited to $10 \mathrm{~s}$, a constant wind speed was assumed for all studies. A schematic of the DFIG model is illustrated in Figure 2.

The dynamic simulation model can be configured to operate at fixed power factor mode or voltage control mode. The DFIG has the fault ride-through (FRT) capability, in which grid-side converter (GSC) operates as a static-synchronous compensator (STATCOM) and crowbar protection is used as an auxiliary protection scheme to protect the RSC during large faults. Modelling of DFIGs for dynamic and stability studies are well documented in the published literature [26-27], thus for brevity the simulation model will not be fully exemplified in this paper.

Active and reactive power control schemes of the RSC and GSC comprised of two control schemes: slow controller and fast current controller. In terms of the GSC an additional droop is implemented within the slow controller, since both controllers control the reactive power at the PCC. A schematic of the RSC controller is shown in Figure 3. 
As illustrated in Figure 3, the error between power references (i.e. $P_{\text {ref }}$ and $Q_{r e f}$ ) and power measurements (i.e. $P_{\text {mea }}$ and $Q_{m e a}$ ) are calculated within the slow controller, and fed through the internal PI controller to generate the appropriate current references (i.e. $I_{r q}$ and $I_{r d}$ ). At the RSC controller, the rotor currents are determined in the statorflux oriented reference frame; hence the q-axis component of the rotor current is controlled in order to control the active power, while the $d$-axis component of the rotor current is controlled in order to control the reactive power. Furthermore, it should be noted that the DIgSILENT Power Factory power electronic converter models require separate modulation indices for both $d$-axis and q-axis, hence they must be calculated separately by the controller in order to independently control the active and reactive power. Therefore, once the corresponding current references are determined they are compared against the corresponding current measurements, and subsequently use to derive the required modulation indices (i.e. $m_{r q}$ and $m_{r d}$ ) for the RSC. Moreover, it is imperative to discuss the reactive power control strategies incorporated to the DFIG, since the DFIG model used in this work can be configured to operate either in fixed power factor or voltage control modes. Figure 4 illustrates the voltage and power factor control schemes of the DFIG.

where, $P_{a v g}, Q_{p f_{-} r e f}, Q_{v_{-} r e f}, V_{\text {mea }}, V_{\text {ref }}, K_{v r e f}, T_{\text {vref }}$ and $p f$ denote the average active power output of the DFIG, the reactive power reference for the power factor control strategy, the reactive power reference for the voltage control strategy, voltage measurement at the PCC, reference voltage, voltage controller gain, voltage controller time constant, and the power factor reference respectively. According to Figure 4, based on the selected control strategy, $Q_{r e f}$ is obtained from the designated control scheme.

\section{Large Disturbance Rotor Angle Stability (Transient Stability) Analysis}

Classical transient stability studies are based on rotor angles measured against their local bus voltages. However for a multi-machine power system the angular separation between synchronous generators is an important factor to maintain transient stability, since when the maximum rotor angle difference (MRAD) between 
two generators or a group of generators exceeds $180^{\circ}$, there will be a high probability of losing stability, due to rapid voltage drop at intermediate points of the network, inflicting voltage instability [28]. In particular, with distributed generation, angular separation between machines may increase; hence it is important to define the rotor angles in terms of a common reference frame.

\subsection{Transient Rotor Angle Severity Index (TRASI)}

Typically for a multi-machine power system the rotor angles are measured against their local bus voltage, and therefore stability is analysed as a local phenomenon in conventional methods during transient conditions. Typically, in a power system, voltage phase angles vary (if transformer phase shifts are neglected) across the network, and during grid disturbances voltage phase angle distributions are highly variable due to the transient currents in the network. Therefore, rotor angle measurements taken in a local reference frame are highly prone to misjudgement of transient stability under such circumstances. The rotor angle can be specified w.r.t. to several reference frames such as:

- Rotor angle w.r.t. local bus voltage $\left(\delta_{\text {local }}\right)$

- Rotor angle w.r.t. slack-bus (reference machine) voltage angle $\left(\delta_{\text {ref_}} v\right)$

- Rotor angle w.r.t. slack-bus (reference machine) rotor angle $\left(\delta_{\text {ref_}} m\right)$

The relative rotor angle measurements can be represented using a vector diagram as illustrated in Figure 5.

$\delta_{\text {ref, }} \delta_{\text {ref_v }}, \delta r_{\text {ef_ } m}, \delta_{\text {local }}$, and $\alpha$ denote the reference machine rotor angle, the rotor angle w.r.t. the reference machine voltage angle, the rotor angle w.r.t. the reference machine rotor angle, the rotor angle w.r.t. the local bus voltage, and the generator bus voltage angle (a-axis) w.r.t. the reference machine voltage angle (a-axis), respectively. The relative rotor angle can be specified based on the reference machine angle, and provides a better stability indicator, since it incorporates the local rotor angle and voltage angle of a particular machine in the network, this can be denoted as follows [15]. 
$\delta_{\text {ref_v }}=\delta_{\text {local }}+\alpha$

$\delta_{\text {ref_m } m}=\delta_{\text {local }}+\alpha-\delta_{\text {ref }}$

Furthermore, during transient disturbances, the rotor angle separation between generators in the system depends on the loss of electromagnetic forces acting at a generator terminal and changes in phase angle due to high currents flowing in the network. Therefore, the maximum rotor angle difference $\left(\delta_{\max \_} d\right)$ can be specified based on the rotor angles measured w.r.t. the reference machine angle as follows:

$$
\begin{aligned}
\delta_{\text {max }_{-} d}(t)= & \max \left[\delta_{r e f_{-} m 1}(t)+\delta_{r e f_{-} m 2}(t)+\delta_{\text {ref_m3 }}(t)+\ldots+\delta_{r e f_{-} m n}(t)\right]- \\
& \min \left[\delta_{r e f_{-} m 1}(t)+\delta_{r e f_{-} m 2}(t)+\delta_{r e f_{-} m 3}(t)+\ldots+\delta_{r e f_{\_} m n}(t)\right]
\end{aligned}
$$

During transient grid disturbances the maximum rotor angle difference can vary between $0^{\circ}$ to $360^{\circ}$ depending upon fault severity and the network strength as seen by the synchronous generators. The ability to evaluate rotor angle instability based on $\delta_{\text {max } \_d}$ is demonstrated considering two different faults in the New England 39 bus system (see Figure 6).

According to Figure 6-(a), following a fault in the network, rotor angle of all ten synchronous generators have regained their equilibrium while the $\delta_{\max } d$ has also recovered to the steady-state condition during the post fault period. Contrary, in Figure 6-(b), four synchronous generators have fallen out-of-step during the post fault period while $\delta_{\text {max } \_d}$ has reached $180^{\circ}$, which confirms the proposed angle is an accurate method to evaluate stability of the network.

An index was defined using the maximum rotor angle difference to analyse the severity of the angular separation between synchronous generators in a network following a $150 \mathrm{~ms}$ three-phase short-circuit fault. The transient rotor angle severity index (TRASI) is defined as follows:

Transient Rotor Angle Severity Index $($ TRASI $)=\left(\frac{360^{\circ}-\max \left(\delta_{\text {ma }_{\_} d}^{p s t}\right)}{360^{\circ}-\delta_{\text {max }_{-} d}^{\text {re }}}\right)$ 
$\delta_{\text {max }_{-} d}^{p s t}$ and $\delta_{\max _{-} d}^{\text {pre }}$ represent the post-disturbance and pre-disturbance maximum rotor angle difference in the network respectively (see Figure 7). During transient disturbances the synchronous generator rotor angles (w.r.t. the reference machine angle) can vary between $180^{\circ}$ to $-180^{\circ}$. Therefore, theoretically, the maximum angle difference can be $360^{\circ}$ during a transient fault.

The TRASI is a comparative measure of rotor angle separation between synchronous generators in the network following a transient grid fault. The index varies from 0 to 1 , with values closer to one considered to be more stable, since the angular separations between the synchronous machines in the system are less compared to the pre-fault values. A similar index is used in DSA PowerTech tools (Transient Stability Index (TSI), however rotor angles are measured w.r.t. local bus voltage angle [29]. The TRASI and TSI were calculated for 150 ms short-circuit faults in the New England-39 bus system, and the calculated indices are listed in Table 2. It must also be noted that the individual rotor angles are measured between $+180^{\circ}$ and $-180^{\circ}$ during an out-of-step condition, and the rotor angle will not be aggregated for each revolution deviated from its steady-state position.

Table 2: Comparison of TRASI and TSI

\begin{tabular}{c|c|c}
\hline \hline & TRASI & TSI \\
\hline Area 1(Bus 6) & 0.977 & 0.782 \\
\hline Area 2(Bus 18) & 0.964 & 0.764 \\
\hline Area 3(Bus 19) & 0.969 & 0.771 \\
\hline Area 4(Bus 21) & 0.980 & 0.787 \\
\hline Area 5(Bus 28) & 0.884 & 0.659 \\
\hline \hline
\end{tabular}

According to Table 2, both indices have indicated the same best (i.e. Area 4-Bus 21 fault) and worst (i.e. Area 5-Bus 28 fault) stability scenarios for the New England 39 bus system, hence it can be concluded that the proposed index for the transient stability assessment is in close agreement with TSI. Furthermore, in order to simulate 
an unstable scenario a $465 \mathrm{~ms}$ three-phase short-circuit fault has been applied at bus 19 of the network, and it has indicated a TRASI of 0.54 while the TSI for that particular scenario was 0.33 .

\section{Voltage Stability Analysis}

\subsection{Transient voltage collapse proximity (TVCP) index}

During large system disturbances, reactive power demand increases, in particular with wind generation (mainly due to FSIGs and DFIGs during crowbar activation) while creating large voltage dips across the network. As a consequence voltage sensitivity to reactive power is a critical factor in order to maintain voltage stability during post-fault period. The V-Q curve represents bus voltage sensitivity to reactive power during the steady-state. A study presented by Chowdhury and Taylor [30] argued that voltage stability analysis based on V-Q curve may misleading mainly due to time dependent control aspects are not incorporated into instability assessment, hence it is imperative to evaluate voltage stability using dynamic simulations. The presented method consider both instability point in the V-Q curve and V-Q trajectory during dynamic conditions to determine the proximity to voltage instability of a given network node during a grid disturbance.

Consider a simple test system shown in Figure 8, which is comprised of a transmission line having a significantly large reactance, a load and a wind farm. For the test system shown in Figure 8, assume that the load power consumption is larger than the power generation at the wind farm; hence we can define net active and reactive power at the busbar $B_{R}$ as;

$$
\begin{aligned}
& P_{N}=\left(P_{L}-P_{G}\right)>0 \\
& Q_{N}=\left(Q_{L}-Q_{G}\right)>0
\end{aligned}
$$

The following equation can be derived for the power transfer at the receiving end (busbar $B_{R}$ ) of the line [31]; 


$$
\begin{aligned}
P_{N} & =-\frac{V_{S} V_{R}}{X} \sin \theta \\
Q_{N} & =-\frac{V_{R}{ }^{2}}{X}+\frac{V_{S} V_{R}}{X} \cos \theta
\end{aligned}
$$

In order to derive the $\mathrm{V}-\mathrm{Q}$ curve, for a range of receiving end voltages $\left(V_{R}\right)$, angle $\theta$ is first computed (assuming constant active power $P_{N}$ ), and then the corresponding reactive power $Q_{N}$ is derived. It is further assumed that sending voltage $V_{S}$ (busbar $B_{S}$ ) is stiff in comparison to the $V_{R}$ (busbar $B_{R}$ ). However, if the majority of the local demand is satisfied by the local generation (which is very likely for a system with high distributed wind generation), then we can assume that $\cos \theta \approx 1$, hence $Q_{N}$ in Eqn. (5) becomes;

$$
Q_{N}=-\frac{V_{R}^{2}}{X}+\frac{V_{S} V_{R}}{X}
$$

At the V-Q instability point; $\frac{d Q_{N}}{d V}=0$, hence (6) becomes;

$$
\frac{d Q_{N}}{d V_{R}}=-\frac{2 V_{R}}{X}+\frac{V_{S}}{X}=0
$$

Therefore, at the point of instability occurs when;

$$
V_{R}=<\frac{V_{S}}{2}
$$

Hence, if the receiving end voltage decreases below $\frac{V_{S}}{2}$ any increase in reactive power can't retrieve the receiving end voltage unless net active power injection is increased (i.e. $P_{N}$ become closer to zero or negative). This is unlikely for a system with distributed wind generation, since wind generators harvest maximum power from the available wind resources as they operate at the maximum power point (MPP), hence can't increase active power production as conventional generators. Moreover, as the shortcircuit fault occurs, wind generator MPP moves away from the optimal value [25], hence it will take considerable time to (1 $-5 \mathrm{~s})$ recover back to the pre-fault steadystate active power production. Therefore, it is unlikely that wind generation will increase $P_{N}$ during both steady-state and transient operating conditions. 
Furthermore, Eqn. (6) can be rearranged in the following form;

$$
\begin{aligned}
& \frac{V_{R}^{2}}{X}-\frac{V_{S} V_{R}}{X}+Q_{N}=0 \\
& V_{R}^{2}-V_{S} V_{R}+X Q_{N}=0
\end{aligned}
$$

The general solution for receiving end voltage $V_{R}$ can be written as;

$$
V_{R}=\frac{V_{S} \pm \sqrt{V_{S}^{2}-4 X Q_{N}}}{2}
$$

Thus, for $V_{R}$ to stabilise at a feasible value, following condition must be satisfied;

$$
\frac{V_{S}^{2}}{4 X}>Q_{N}
$$

According to (11), as long as $Q_{N}$ is lesser than $\frac{V_{S}^{2}}{4 X}$, receiving end voltage will stabilise in the stable region. As the fault occurs, $Q_{N}$ is likely to vary significantly due to the dynamics associated with load and generation connected to the busbar [31]. In particular, reactive power consumption of an induction machine load (i.e. $Q_{L}$ will increase, hence the $\left.Q_{N}\right)$ will increase during the post-fault period [31]. Thus, if no reactive power support is provided by the wind generator $\left(Q_{G}\right)$, it doesn't result in any feasible steady-state voltage at the receiving end (busbar $B_{R}$ ). However, if reactive power support is provided by the wind generator (through voltage control strategy and power factor control strategy), then it will lessen $Q_{N}$, hence it will more likely to result in a feasible steady-state voltage at the receiving end. Therefore, reactive power control strategy is an important determinant for the V-Q based voltage stability. Consider four scenarios listed in Table 3 for the test network shown in Figure 8. 
Table 3: Test scenarios for V-Q stability boundary verification

\begin{tabular}{c|c|c|c|c|c}
\hline \hline & $\mathrm{V}_{\mathrm{S}}(\mathrm{pu})$ & $\mathrm{X}(\mathrm{pu})$ & $\mathrm{P}_{\mathrm{N}}(\mathrm{pu})$ & $\mathrm{V}_{\mathrm{S}} / 2(\mathrm{pu})$ & $\frac{V_{S}^{2}}{4 X}$ \\
\hline Scenario 1 & 1 & 0.10 & 0.01 & 0.5 & 2.5 \\
\hline Scenario 2 & 1 & 0.05 & 0.10 & 0.5 & 5.0 \\
\hline Scenario 3 & 1 & 0.10 & 0.50 & 0.5 & 2.5 \\
\hline Scenario 4 & 1 & 0.10 & 0.80 & 0.5 & 2.5 \\
\hline \hline
\end{tabular}

V-Q curves were generated for scenarios shown in Table 3 while varying the $V_{R}$ from $1.05 \mathrm{pu}$ to $0.1 \mathrm{pu}$, and then the stability boundaries were also plotted together with the V-Q curve (see Figure 9).

As illustrated in Figure 9, four quadrants can be identified around the V-Q instability point (i.e. $\frac{d Q_{N}}{d V}=0$ ). Also, it can be observed that when $P_{N}$ is a larger value (i.e. when the power import is a larger value) stability boundary defined by $\left(\frac{V_{S}^{2}}{4 X}\right)$ moves slightly away from the instability point (due to the assumption made on $\theta$ when deriving the Eqn. (8)). However, when distributed wind generation increases it will decrease power import from the transmission network (i.e. when $P_{N}$ decreases), and subsequently the derived stability boundaries are in close agreement with the V-Q curve.

A generic V-Q curve is illustrated in Figure 10. $V_{S S}, V_{D V}, V_{Q V}, Q_{S S}, Q_{D V}$ and $Q_{Q V}$ denote steady-state bus voltage, dynamic bus voltage, voltage at the V-Q instability margin, steady-state reactive power, dynamic reactive power and reactive power at the V-Q instability margin respectively. During steady-state conditions bus voltage will vary along the $\mathrm{V}-\mathrm{Q}$ curve based on reactive power variation at the busbar for a constant active power demand. During a large system disturbance, the network bus voltages are depressed while increasing the reactive power demand of the network, hence operating point moves away from the steady-state operating point $\left(L_{1}\right)$. The V-Q 
trajectory during a network fault is largely based on the load dynamics and reactive power control schemes of the distributed wind generation systems at the busbar. The point $L_{3}$ (i.e. dynamic operating point) can move in the four quadrants defined around the V-Q instability margin during the post-fault period. However, as illustrated in Figure 10, it is infeasible to stabilise the bus voltage in three quadrants, since they violate the stability boundaries defined in (8) and (11). Therefore, a sensitivity index was derived based on relative proximity of the steady-state operating point $\left(L_{1}\right)$ and the dynamic operating point $\left(L_{3}\right)$ towards the V-Q instability margin $\left(L_{2}\right)$, which can be defined as follows:

$$
T V C P I=(+/-) \frac{P_{D V}}{P_{S S}}
$$

$P_{S S}$ and $P_{D V}$ denote the steady-state and dynamic bus voltage proximity to V-Q instability margin respectively, and they are defined as follows:

$$
\begin{aligned}
& P_{S S}=\sqrt{\left(V_{S S}-V_{Q V}\right)^{2}+\left(Q_{S S}-Q_{Q V}\right)^{2}} \\
& P_{D V}=\sqrt{\left(V_{D V}-V_{Q V}\right)^{2}+\left(Q_{D V}-Q_{Q V}\right)^{2}}
\end{aligned}
$$

Furthermore, a sign convention was also defined based on the quadrant. The TVCPI becomes negative when either $\left(V_{R}=<\frac{V_{S}}{2}\right)$ or $\left(\frac{V_{S}^{2}}{4 X}>Q_{N}\right)$ violated by the dynamic operating point. A large negative TVCPI indicates likely voltage instability issue in the network. It should also note that reactive power was normalised based on the absolute reactive power demand at the $\mathrm{V}-\mathrm{Q}$ instability point. This method incorporates the influence of reactive power and voltage control devices (i.e. synchronous generators/ condensers, automatic tap changing transformers, static VAr compensators (SVCs), static-synchronous compensators (STATCOMs) and capacitor banks) on V-Q trajectory during dynamic conditions and its proximity to static V-Q instability margin. Therefore, if the dynamic Q-V trajectory is traced it can able to evaluate the proximity to the steady-state voltage instability point, however dynamic nature of the control 
devices enable it to recover from the instability regions defined around the $\mathrm{Q}-\mathrm{V}$ instability point (Figure 10). Nevertheless if the dynamic control devices reach their maximum limit such as maximum tap position, maximum reactive power limit of the SVCs and STATCOMs, and over-excitation limit (OEL), and subsequently Q-V trajectory will never recover back from the unstable regions. Thus, TVCPI can be used as a robust voltage stability indicator for a wind rich network.

In order to further validate the index, two fault scenarios have been simulated using the New England-39 bus system. Figure 11 illustrates the V-Q curve and V-Q trajectory of buses 24 and 28 during a fault at area 5 (bus 21) in the New England -39 bus system. The V-Q trajectory for bus 24 has moved away from the V-Q instability margin during the fault while creating voltage stability issues in the network (see Figure 11-(a)). The TVCPI becomes negative during the fault, and soon after fault is cleared it has further reduced due to the deteriorated voltage recovery response at bus 24. According to Figure 11-(b), the V-Q trajectory is within the positive region of V-Q curve; hence it is less likely to cause voltage instability during the post-fault period. As illustrated in Figure 11-(b), the TVCPI is also positive during the fault.

\section{Case Study: Stability Analysis of a Wind Rich Interconnected Network}

The MATPOWER optimal power flow (OPF) functionality [32] has been used to derive generation dispatch while using wind and load distribution scenarios obtained through scenario reduction technique in [21]. A base voltage of $110 \mathrm{kV}$ was assumed for the NE-39 system, while +/- $0.05 \mathrm{pu}$ voltage variation was allowed during OPF. Furthermore, for each scenario it is assumed that all wind generators are online, except for very low wind scenarios $(<2 \%)$. Therefore, the required wind dispatch is achieved by varying the power output of the each wind generator. It is assumed that CCGT and steam turbine (ST) units have $40 \mathrm{MW}$ spinning reserve response while OCGTs are assumed to have $25 \mathrm{MW}$ reserve response. The total system reserve was set approximately equal to the size of the largest conventional plant dispatch level and exact value varies from one scenario to another. 


\subsection{Characteristics of Dispatch Case Studies}

The penetration levels of wind, CCGT and other conventional generation, and their associated probabilities for dispatch cases are illustrated in Figure 12-(a). The associated probability was determined based on the historical data for a real power network. It should be noted that penetration level was determined as a ratio of the load demand for each dispatch case. According to Figure 12-(a), the aggregated wind and CCGT/OCGT penetration level is more than 50\% for all scenarios, hence wind and CCGT/OCGT dynamics are of paramount importance when determining the stability of the network.

Wind integration directly affects the system inertial response due to the decoupled nature of the power electronic converter system of the DFIG; hence system inertia is extremely important for system frequency stability. An average inertia constant for each area was calculated considering both synchronous and wind generation (see Figure 12-(b)). However, inertia constant for the DFIG wind generator was assumed to be zero as their electromechanical dynamics are decoupled from electrical dynamics. According to Figure 12-(b), a significant difference in inertia can be observed for various regions in the network; in particular areas 1 and 2 depict the largest inertia variation across all dispatch scenarios. This is due to the fact that the generating resources of those regions are mainly comprised of inertialess wind generation.

\subsection{Transient stability analysis for dispatch scenarios}

For each dispatch scenario, a three-phase short-circuit fault was initiated in each area of the network and TRASI was calculated. It is assumed that wind generators are operating at constant power factor mode. Figure 13 illustrates the TRASI of each region for ten dispatch scenarios considering a $150 \mathrm{~ms}$ three-phase short-circuit fault in each region. According to Figure 13 transient stability has worsen when a fault occurs in Area 5. This is mainly due to the dynamic interactions between wind and conventional generation in area 5 . 
This phenomenon can be explained as follows: When a fault occurs in area 5 (bus 21) it significantly affects the wind generation due to the voltage reduction across the region. In particular, active power production has significantly impaired during the fault and substantial reactive power is absorbed by the wind generators due to crowbar activation. This has deteriorated the voltage recovery profile across Area 5 while leading to large rotor angle deviations as consequence of electromechanical power imbalance at the generator. This is due to the fact that when network voltage decreases it will result in a power imbalance between the electrical power output and mechanical power input to the generator as the electrical power output from the generator depends on the terminal voltage. When the electrical power output is lower than the mechanical power input, it will create an acceleration torque at the generator, hence the generator rotor angle will deviate from the steady-state angle.

For example, a fault in Area 5 has resulted in a severe impact on local wind generation (i.e. DFIG22) while deteriorating the voltage at bus 35 during the post-fault period, and ultimately it has resulted in large rotor angle oscillations at generator at bus 35 (see Figure 14). However, it should be noted that when a fault occurs at Area 2, it has an insignificant impact on post-fault voltage recovery. Thus rotor angle perturbation at the local generator unit (i.e. CCGT38) is insignificant compared to generator at bus 35 , since impact of localised wind generation is substantially low.

The interaction between wind and conventional generation is further evident from Figure 15. According to Figure 15 high penetration of both wind and conventional generation likely to cause transient stability issues due to increased dynamic interactions. As an example, for wind to conventional generation ratio of 0.86 , it has indicated a TRASI of 0.73 , and that has been improved to 0.88 when wind to conventional generation increased to 3.5. This indicates another vital fact that when wind generation is extremely dominant in the network it can improve transient stability of the network. Therefore, network regions with both high wind and conventional generation are likely to result in severe transient stability issues in the 
network, in particular when ratio between wind and conventional generation is closer to 1 .

Furthermore, this study has been extended to specifically analyse the effect of crowbar operation while assuming enhanced FRT (i.e. rotor current transient is not significant to activate the crowbar protection) for DFIG. According to Figure 15-(b), it has indicated an improvement in transient stability; however same transient stability deterioration trend can be seen as observed in Figure 13 for scenarios with significant wind and conventional generation due to reduction in wind generation during local faults. Therefore, despite the improvement in TRASI, stability characteristics due to geographically distributed wind resources remained unchanged during high wind and conventional generation.

In addition, wind generator operating strategy has also been analysed and it has also shown same regional transient stability issues due to geographic distribution of wind resources. It should be noted that wind farms operating at voltage control mode is more beneficial for transient stability, however as the FRT of wind generators enable wind farms to operate at voltage control mode by dispatching reactive power during the fault, the impact on transient stability is marginal.

\subsection{Voltage stability analysis of dispatch scenarios}

The minimum TVCPI was recorded for wind farm buses in area 1 considering the faults in each area for four dispatch cases (i.e. scenario 1, 3, 6 and 9). These scenarios were selected as their wind and conventional generation ratios are significantly different from each other. It is assumed that wind generators are operating at constant power factor mode.

According to Figure 16, local fault is more detrimental on voltage stability, however faults in other regions have also significantly influenced on voltage stability of area 1. As an example, for scenario 6 (wind/conventional=0.89) it has indicated a TVCPI of 3.64 for bus 25 and that has been improved to -1.07 for scenario 9 (wind/ 
conventional=0.1). Similar trend can be observed for wind farms in other network regions, thus for brevity area 1 observations are discussed here. This was due to the fact that geographically distributed wind in other regions absorbs reactive power due to crowbar activation and creates deteriorated voltage profile across the network. In addition, for high wind and conventional scenarios (i.e. scenarios 3 and 6 - refer Figure 15-(a)) have indicated largest voltage instability issues due to aforementioned wind and conventional generation interactions. Therefore, localised high wind generation may trigger voltage stability issues in power networks.

The crowbar protection is an auxiliary protection for modern DFIGs, however extreme fault cases it's likely to operate crowbar protection due to large voltage fluctuations at the DFIG terminals. If DFIGs are capable to mitigate large rotor current transients while avoiding crowbar activation TVCPI can be improved from 1.99 to 1.78 for bus 18 during a fault at bus 18 in scenario 6 .

\subsection{Influence of wind generator control strategy}

When wind generators are operating at fixed power factor $(\mathrm{PF})$ mode, $\mathrm{V}-\mathrm{Q}$ instability limit reaches with less reactive power while for voltage and droop control strategies VQ instability margin moves further away from the steady-state operating point [33]. However, it should be noted that modern DFIGs inject reactive power in order to recover voltage during system contingencies; hence wind generator control strategy during system contingencies is a non-influential factor for V-Q trajectory during the fault.

According to Figure 17, power factor control strategy depicts the worst TVCPI compared to other two strategies. As an example, it has indicated a TVCPI of -2 for bus 18 for PF mode and that has been improved to 0.70 for voltage control mode. However, it should be noted that irrespective of the control strategy the impact of geographically distributed wind generation on voltage stability remain unchanged.

\section{Conclusions}


This study has investigated stability issues with geographically distributed wind resources in a power network using novel stability indices. In particular, a novel voltage stability index was developed to take into account the proximity of the V-Q trajectory to the V-Q instability margin of a network node. In this regard, particular emphasis has been placed on wind farm nodes, since wind farm FRT characteristics will significantly influence network voltage stability. This study has shown that network regions with high penetration of both wind and conventional generation have detrimental stability issues due to their non-complementary characteristics. In contrast, a dominance of either wind or conventional generation can improve transient and voltage stability of the network. Future DFIG wind farms can be equipped with enhanced FRT strategies to mitigate DC link transients, and hence alleviate crowbar activation and improve stability. Nevertheless, existing DFIGs are equipped with conventional FRT techniques, and their penetration levels are substantial in certain network regions, and hence they will still trigger stability issues during network faults in future. The control strategy also influences stability, however stability characteristics associated with network regions remain unchanged irrespective of the control strategy of the wind generator. 


\section{References}

[1] AEMO., '100\% renewables study - modelling assumptions and input' (AEMO, September 2012)

[2] 'Scottish study Scotland aims for $100 \%$ renewable energy by 2020', http://www.smh.com.au/business/carbon-economy, accessed November 2013.

[3] Fox, B., Flynn, D., Bryans, L., Jenkins, N., Milborrow, D., O' Malley, M., Watson, R.: 'Wind Power Integration: Connection and System Operational Aspects' (IEE Power and Energy Series 50, IET: London, 2007)

[4] Ackermann, T.: 'Wind Power in Power Systems' (New York: John Wiley \& Sons Inc., 2012)

[5] Meegahapola, L., Flynn, D.: 'Frequency Dynamics during high CCGT and wind penetrations'. AUPEC 2011, Brisbane, Australia, Sep. 2011

[6] Akhmatov, V., Erilkson, P.B.: 'A large power system in almost island operation-a Danish case study', IEEE Trans. Power Syst., 2007, 22, (3), pp. 937-947

[7] Akhmatov, V., Kundsen, H.: 'Large penetration of wind and dispersed generation into Danish power grid', Electric Power Systems Research, 2007, 77, (9), pp. 1228-1238

[8] Rodriguez, J. M., Fernandez, J. L., Beato, D., Iurbr, R., Usala, J., Ledesma, P., Wilhelmi, J. R.: 'Incidence of power system dynamics of high penetration of fixed speed and doubly-fed wind energy systems: study of Spanish case', IEEE Trans. Power Syst., 2002, 17, (4), pp. 1089-1095

[9] Usala, J., Ledesma, P., Rodriguez, J. M., Fernandez, J. L., Beato, D., Iturbe, R., Wilhelmi, J. R.: 'Transient stability studies in grids with great wind power penetration-modeling issues and operational requirements'. IEEE PES GM 2003, Toronto, Canada, Jul. 2003

[10] Jauch, C., Sorensen, P., Norheim, I., Rasmussen, C.: 'Simulation of the impact of wind power on the transient fault behaviour of the Nordic power system', Electric Power System Research, 2006, 77, pp. 143-136

[11] Meegahapola, L., Flynn, D., and Littler, T.: 'Transient stability analysis of a power system with high wind penetration'. UPEC 2008, Padova, Italy, Sep. 2008

[12] Meegahapola, L., Flynn, D., Kennedy, J., Littler, T.: 'Impact of wind generation mix on transient stability for an interconnected power system'. EWEC 2009, Marseille, France, Mar. 2009

[13] Muljadi, E., Butterfield, C.P., Parsons, B., Ellis, A.: 'Effect of variable speed wind turbine generator on stability of a weak grid', IEEE Trans. Energy Conv., 2007, 22, (1), pp. 29-36

[14] Nunes, M.V.A., Lopes, J.A.P., Zurn, H.H., Bezerra, U.H., Almeida, R.G.: 'Influence of the variable speed wind generators in transient stability margin of the conventional generators integrated in electrical grids', IEEE Trans. Energy Conv., 2004, 19, (4), pp. 692-701

[15] Meegahapola, L., Flynn, D.: 'Impact on transient and frequency stability for a power system at very high wind penetration'. IEEE PES GM 2010, Minneapolis, USA, Jul. 2010

[16] Ullah, N.R., Thiringer, T.: 'Effect of operational modes of a wind farm on the transient stability of nearby generators and on power oscillations: A Nordic grid study', Wind Energy, 2007, 11, pp. 63-73 
[17] Vittal, E., O’Malley, M., Keane, A.: 'Rotor angle stability with high penetrations of wind generation', IEEE Trans. Power Syst., 2012, 27, (1), pp. 353-362

[18] Vittal, E., Keane, A., O’Mally, M.: 'A steady-state voltage stability analysis of power systems with high penetrations of wind', IEEE Trans. Power Syst., 2010, 25, (1), pp.433-442

[19] Gauta006D, D., Vittal, V., Harbour, T.: 'Impact of increased penetration of DFIG-based wind turbine generators on transient and small signal stability of power systems', IEEE Trans. Power Syst., 2009, 24, (3), pp. 1426-1434

[20] EirGrid Plc ., 'All Island TSO Facilitation of Renewables Studies-Work Package 3 Final Report', http://www.eirgrid.com/ren , accessed October 2013

[21] Burke, D.J.: 'A Study of Principal Component Analysis Applied to Spatially Distributed Wind Power', PhD thesis, School of Electrical, Electronic and Mechanical Engineering, UCD, Dublin, Ireland, 2011

[22] IEEE Standard 421.5-2005: 'IEEE Recommended Practice for Excitation System Models for Power System Stability Studies', April 2006

[23] Siemens Power Generation, 'Technical Spec. SWT-2.8-82 VS Wind Turbines', http://www.powergeneration.siemens.com

[24] GE Energy, 'Dynamic Modelling of GE 1.5 and 3.6 Wind Turbine-Generators', 2003

[25] Meegahapola, L.G., Littler, T., Flynn, D.: 'Decoupled-DFIG Fault-ride through strategy during grid faults', IEEE Trans. Sust. Energy, 2010, 1, (3), pp. 152-162

[26] Ekanayake, J.B., Holdsworth, L., XueGuang W., Jenkins, N.: 'Dynamic modeling of doubly fed induction generator wind turbines', IEEE Trans. Power Syst., 2003, 18, (2), pp. 803809

[27] Yazhou L., Mullane, A., Lightbody, G., Yacamini, R.: 'Modeling of the wind turbine with a doubly fed induction generator for grid integration studies', IEEE Trans. Energy Conv., 2006, 21, (1), pp. 257,264

[28] Kundur, P.: 'Power Systems Stability and Control' (New York: McGraw-Hill, 1994)

[29] Powertech Labs, Inc. 'DSA Tools Model Manual', 2006

[30] Chowdhury, B.H., Taylor, C.W.: 'Voltage Stability Analysis: V -Q Power Flow Simulation versus Dynamic Simulation', IEEE Trans. Power Syst., 2000, 15, (4), pp. 1354,1359

[31] Custem, T.V., Vournas, C.: 'Voltage Stability of Electric Power Systems' (Springer Power Electronics and Power Systems Series, New York: Springer, 1998)

[32] Zimmerman, R.D., Murillo-Sánchez, C.E., Thomas, R.J.: 'MATPOWER: Steady-State Operations, Planning and Analysis Tools for Power Systems Research and Education', IEEE Trans. Power Syst., 2011, 26, (1), pp. 12-19

[33] Meegahapola, L.: 'Stability Analysis and Coordinated Control Strategies during High Wind Penetration', PhD thesis, SEEECS, QUB, Belfast, UK, 2010 
Figures

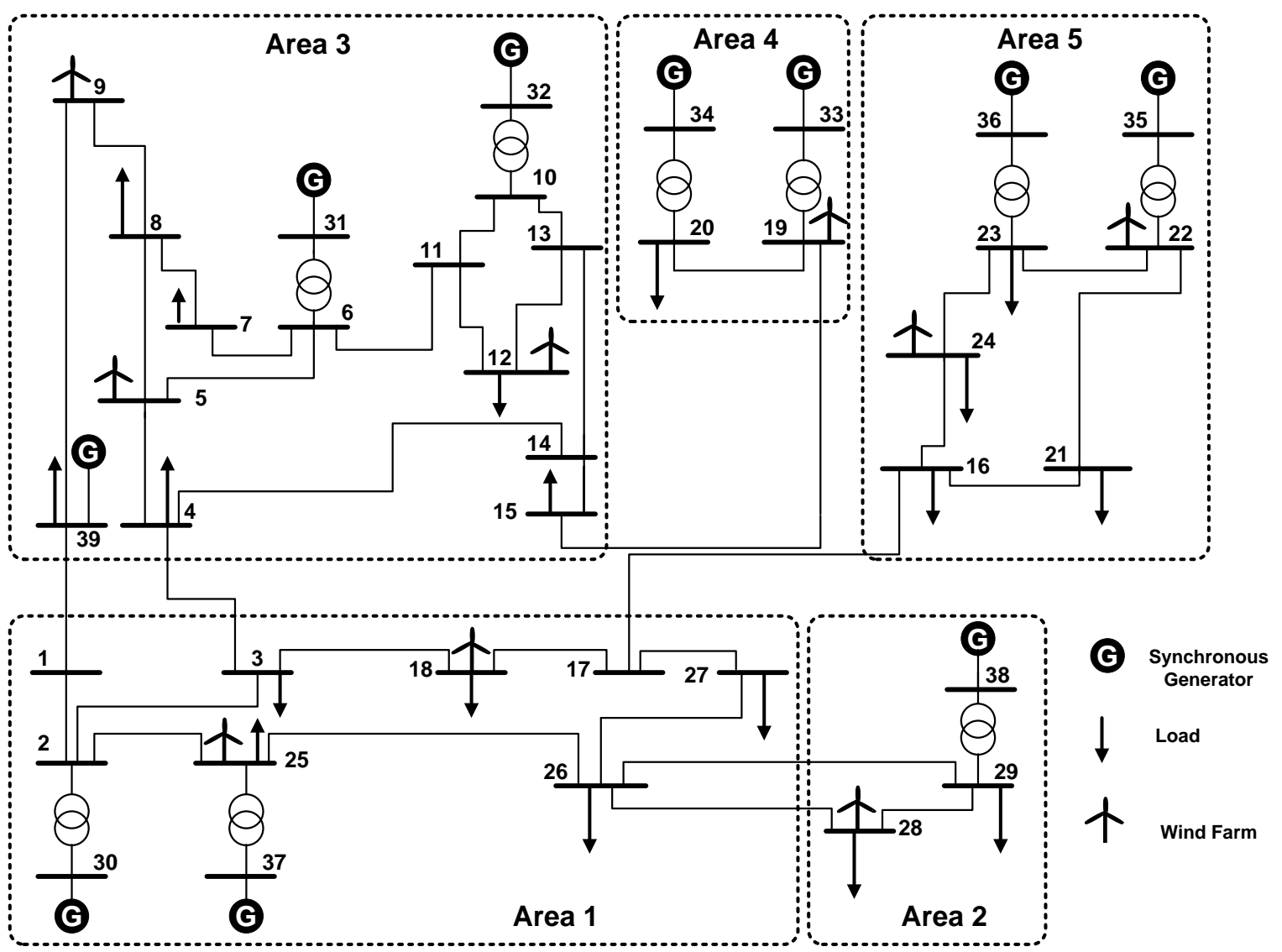

Figure 1: Modified New England-39 bus network.

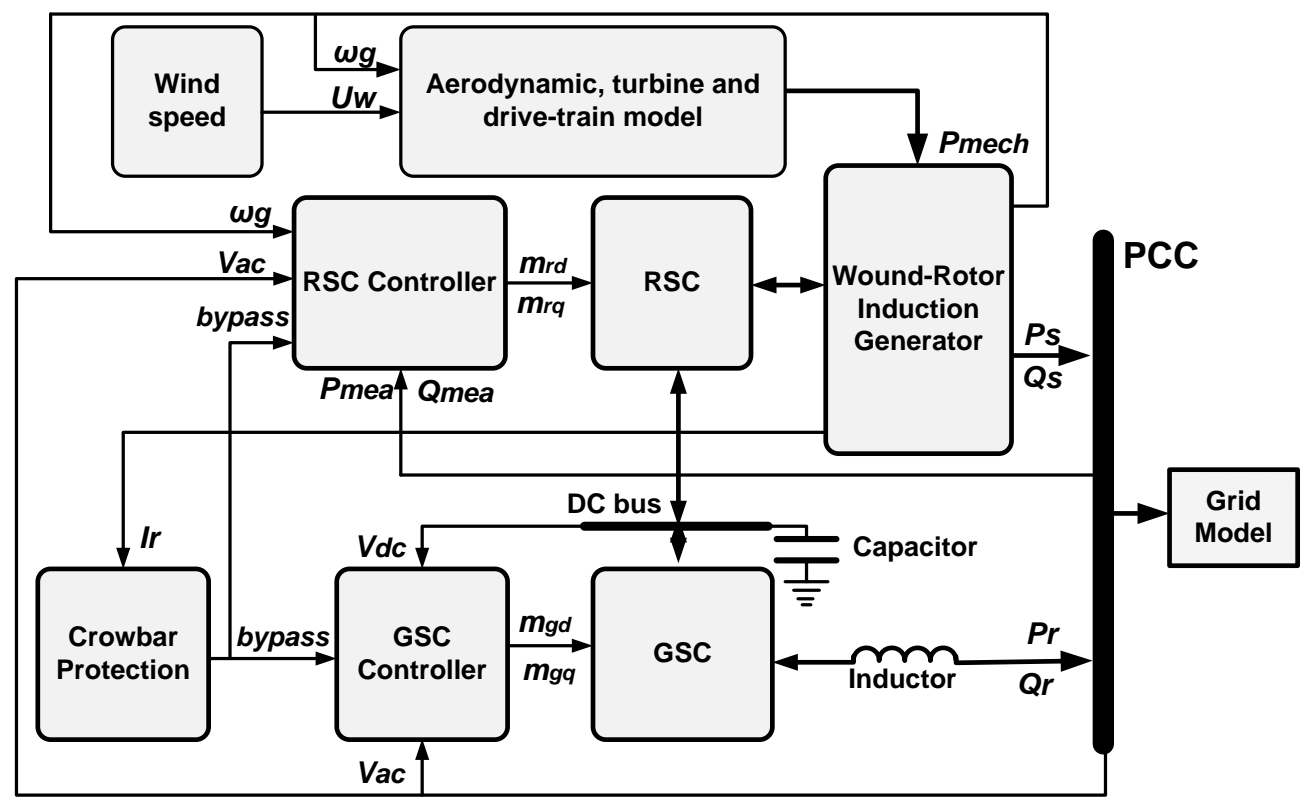

Figure 2: The DFIG simulation model. 


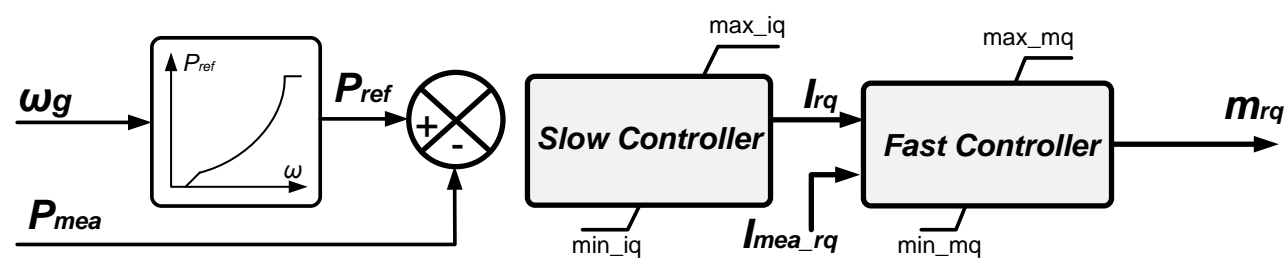

(a)

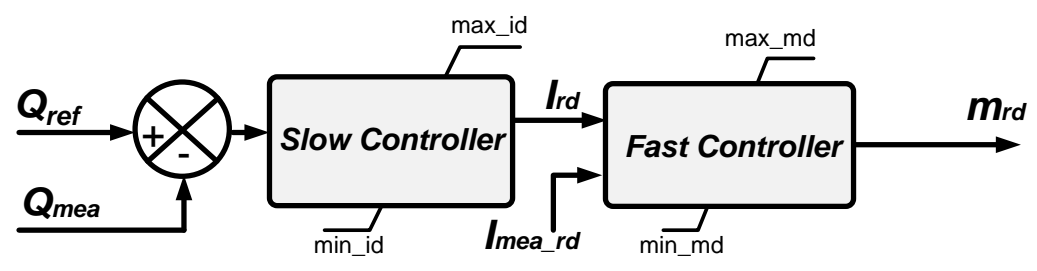

(b)

Figure 3: RSC controller; (a) Active power control scheme (b) Reactive power control scheme.

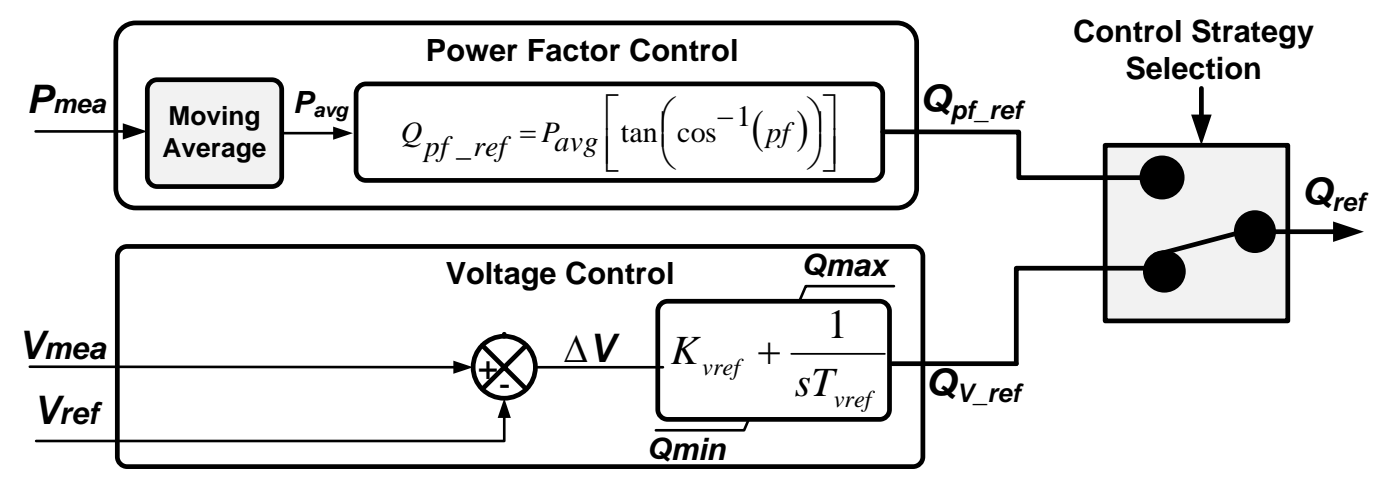

Figure 4: The DFIG voltage and power factor control schemes.

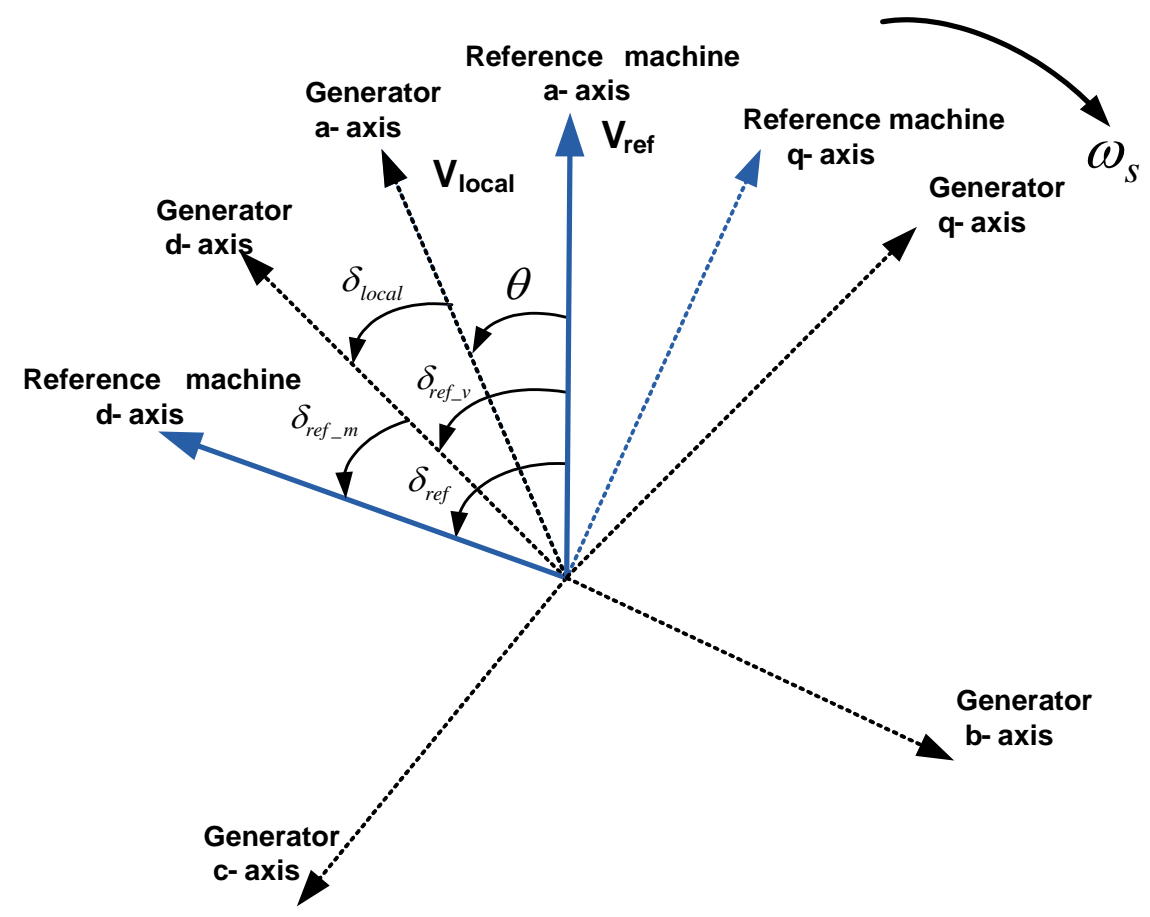

Figure 5: The relative rotor angle measurements. 

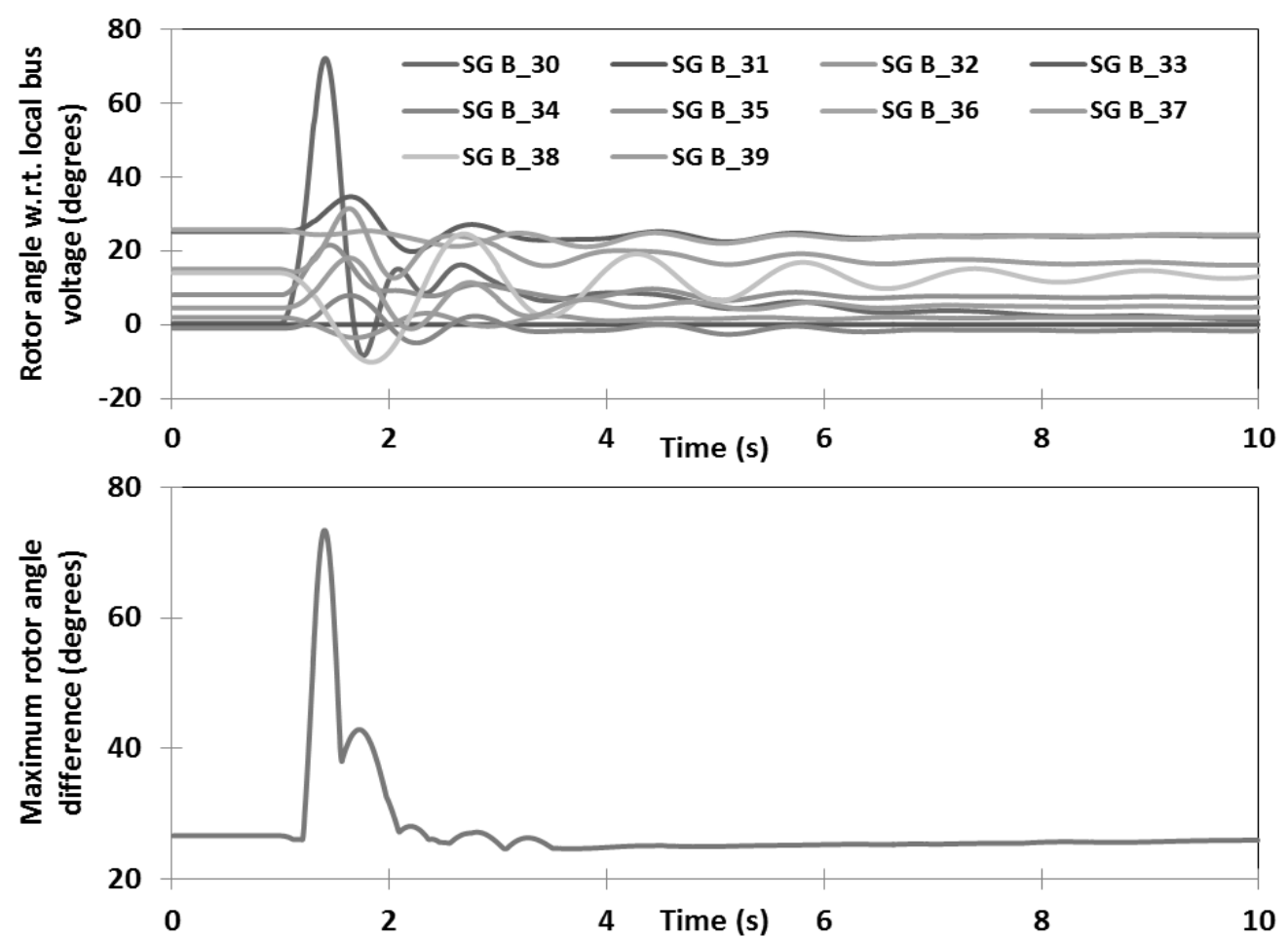

(a)
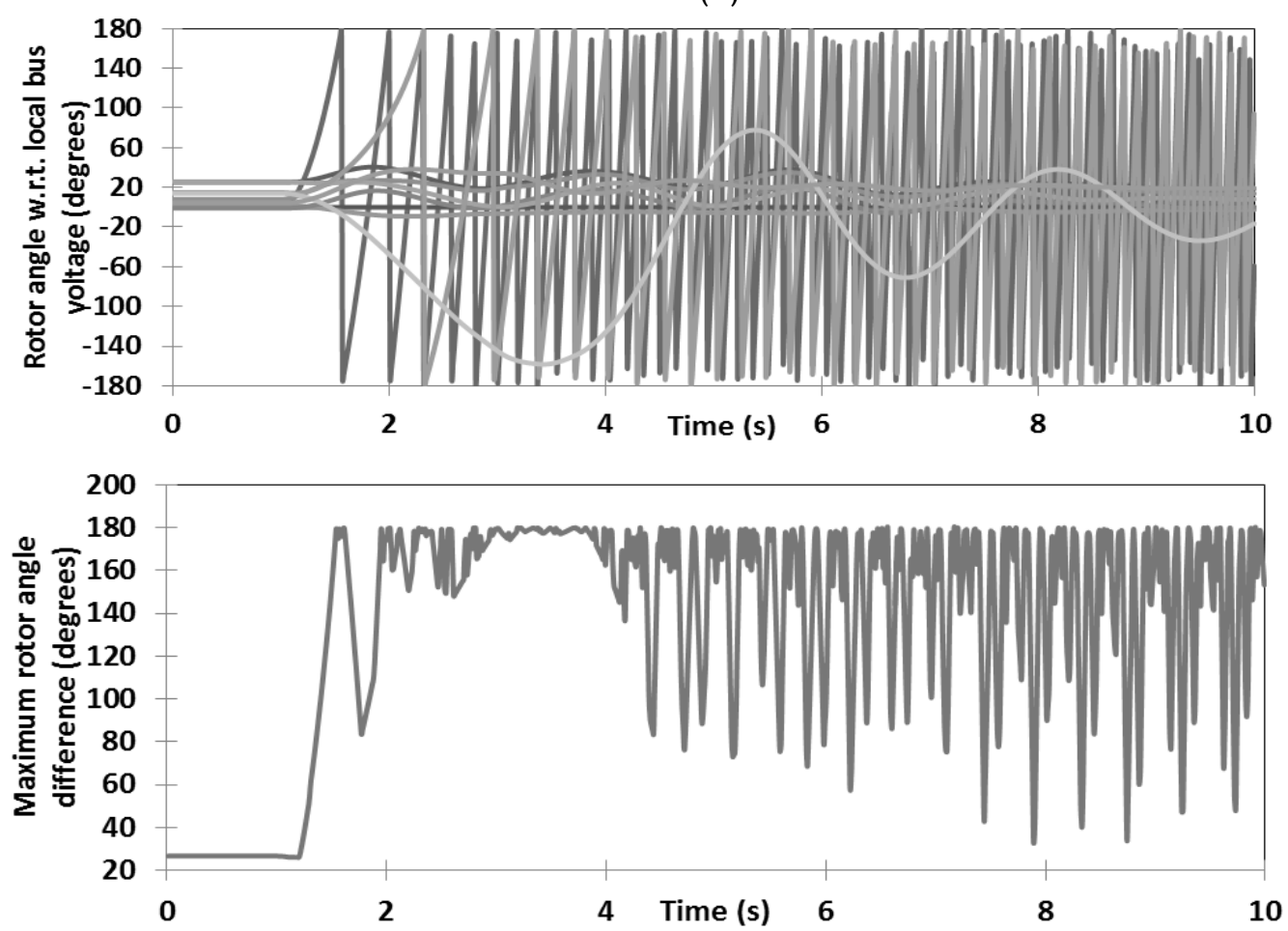

(b)

Figure 6: The New England-39 bus system rotor angle variations; (a) Stability condition, (b) Instability condition. 


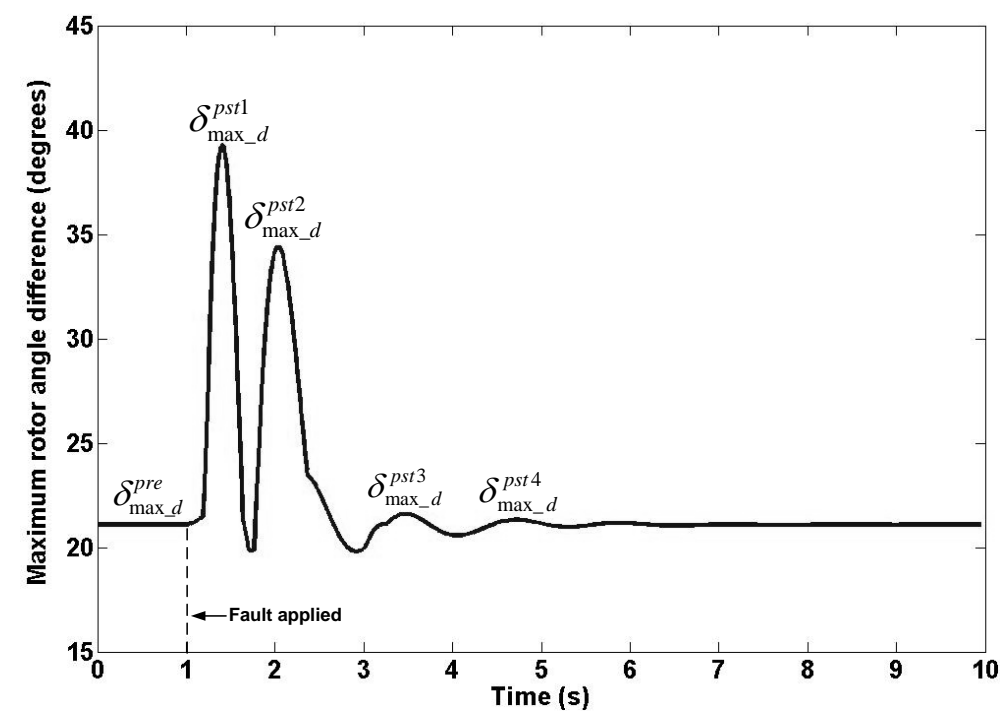

Figure 7: Components of transient rotor angle severity index (TRASI) calculation.

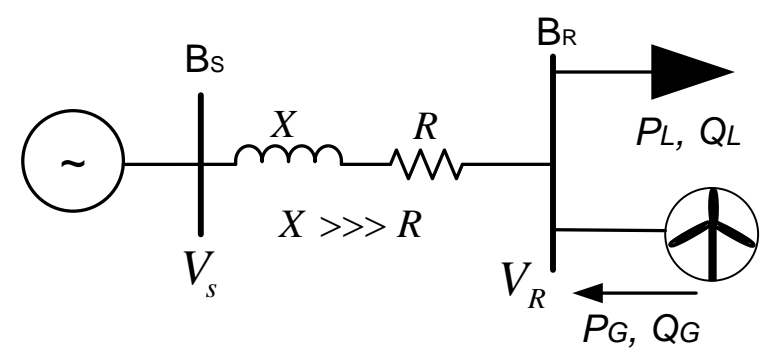

Figure 8: A simple test system.

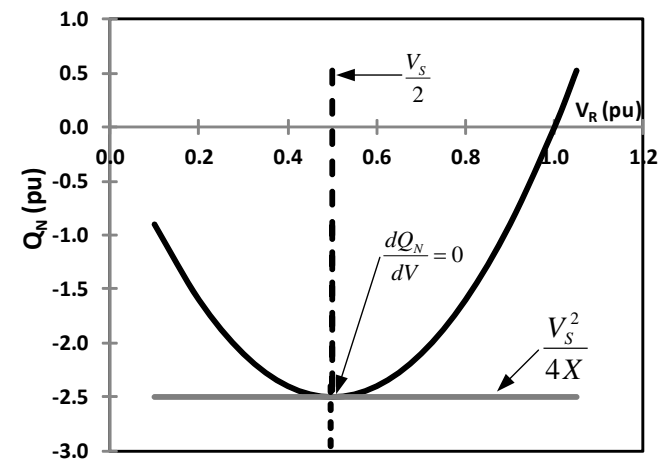

(a)

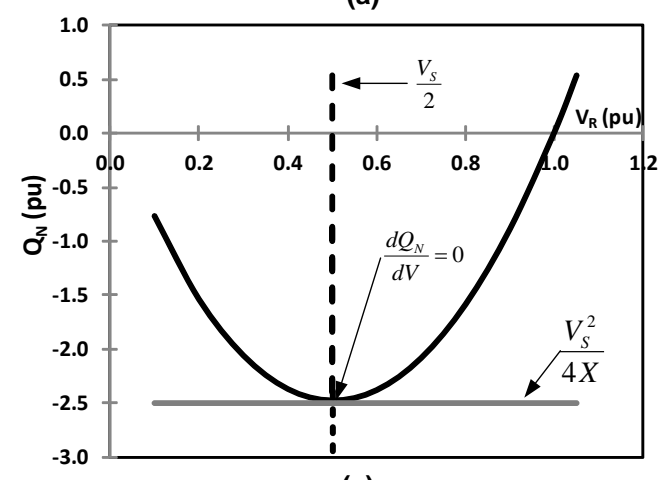

(c)

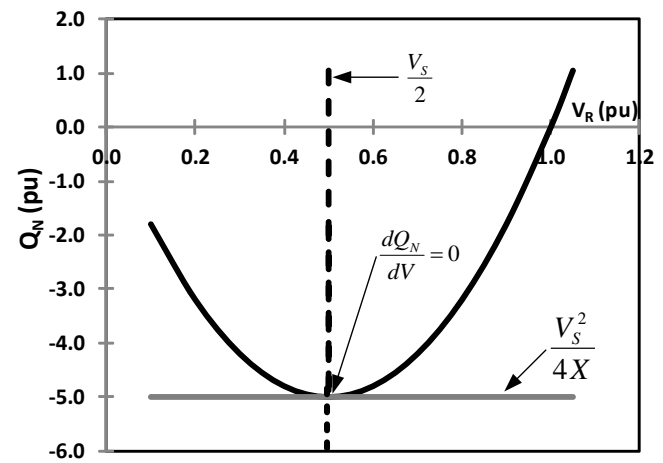

(b)

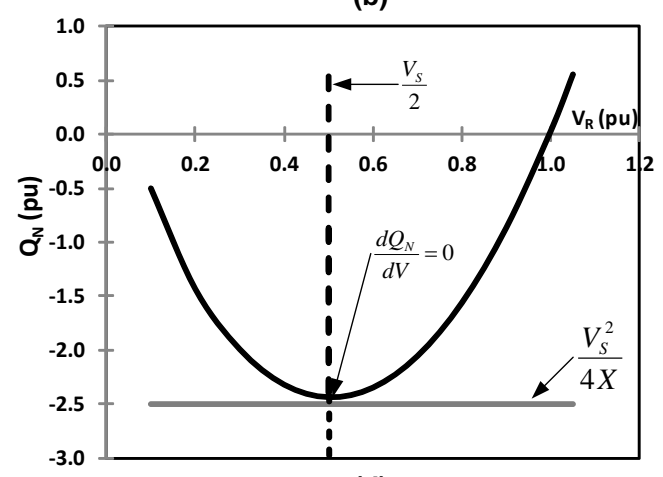

(d)

Figure 9: V-Q curves for scenarios; (a) Scenario 1, (b) Scenario 2, (c) Scenario 3, (d) Scenario 4. 


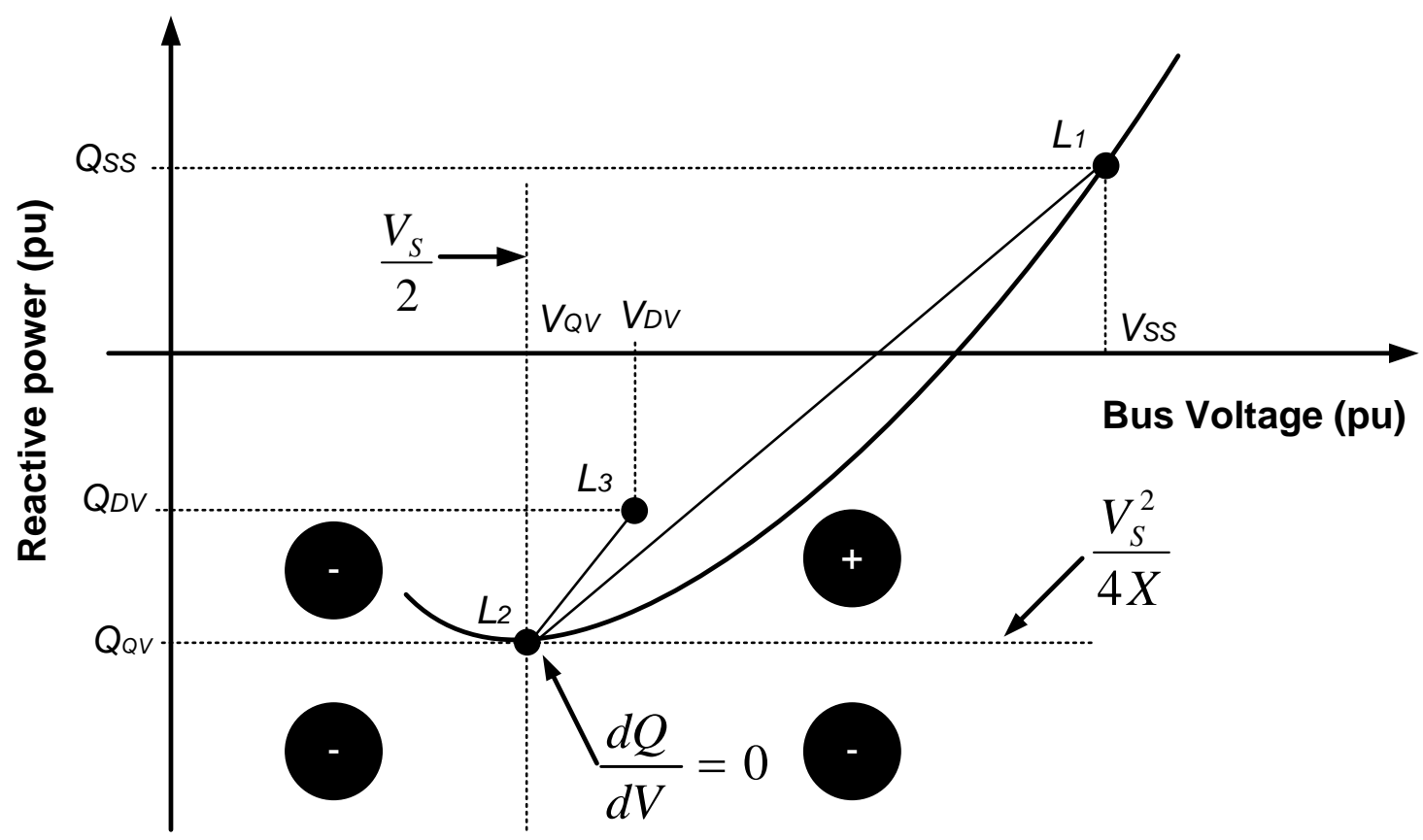

Figure 10: Voltage stability assessment V-Q curve.
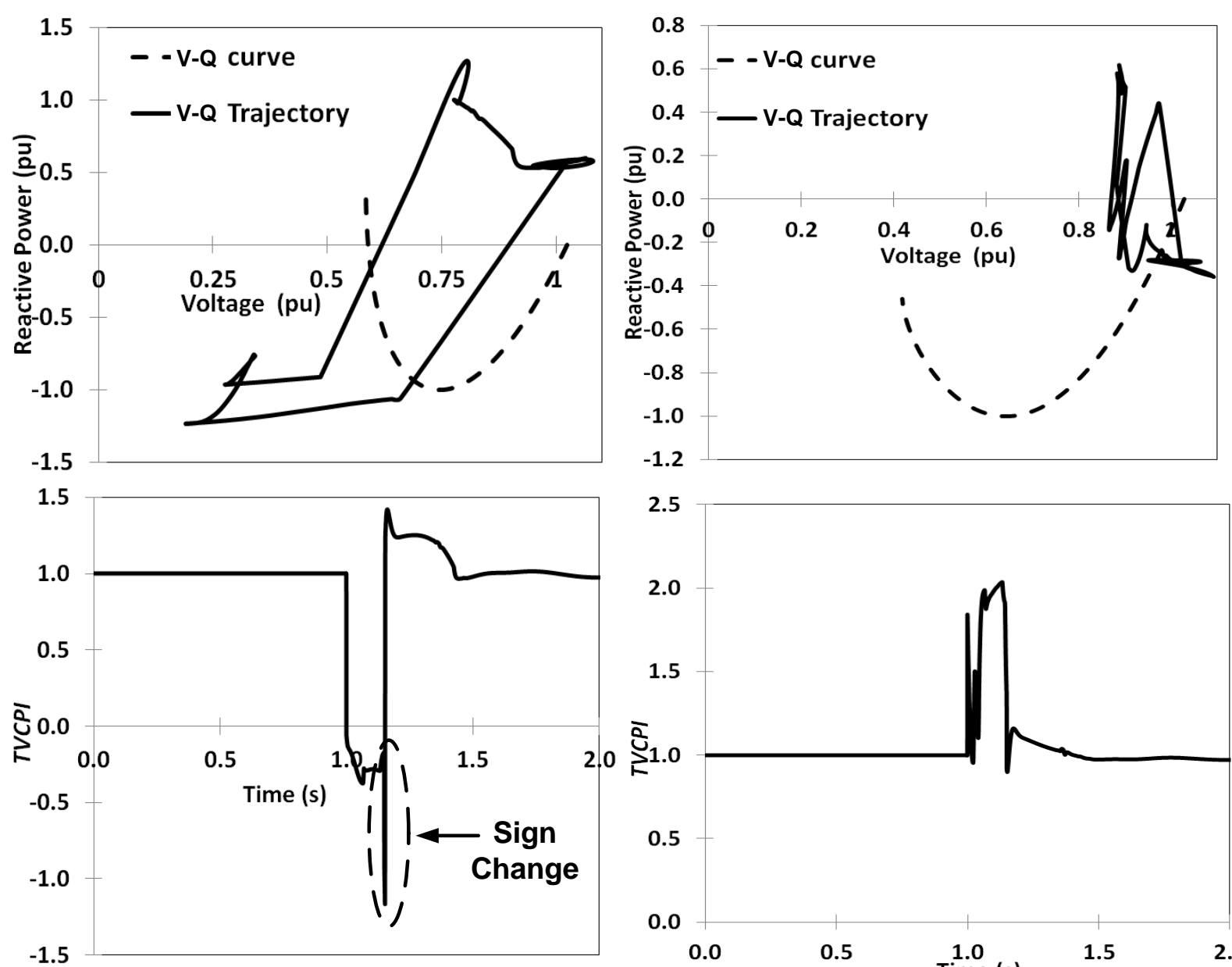

(a)

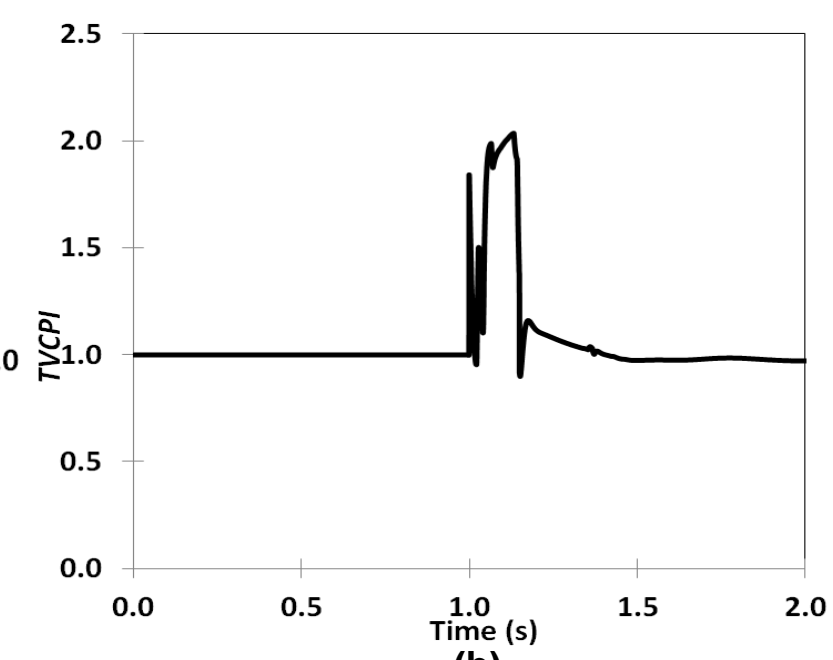

(b)

Figure 11: Verification of TVCPI (a) Bus 24; (b) Bus 28. 


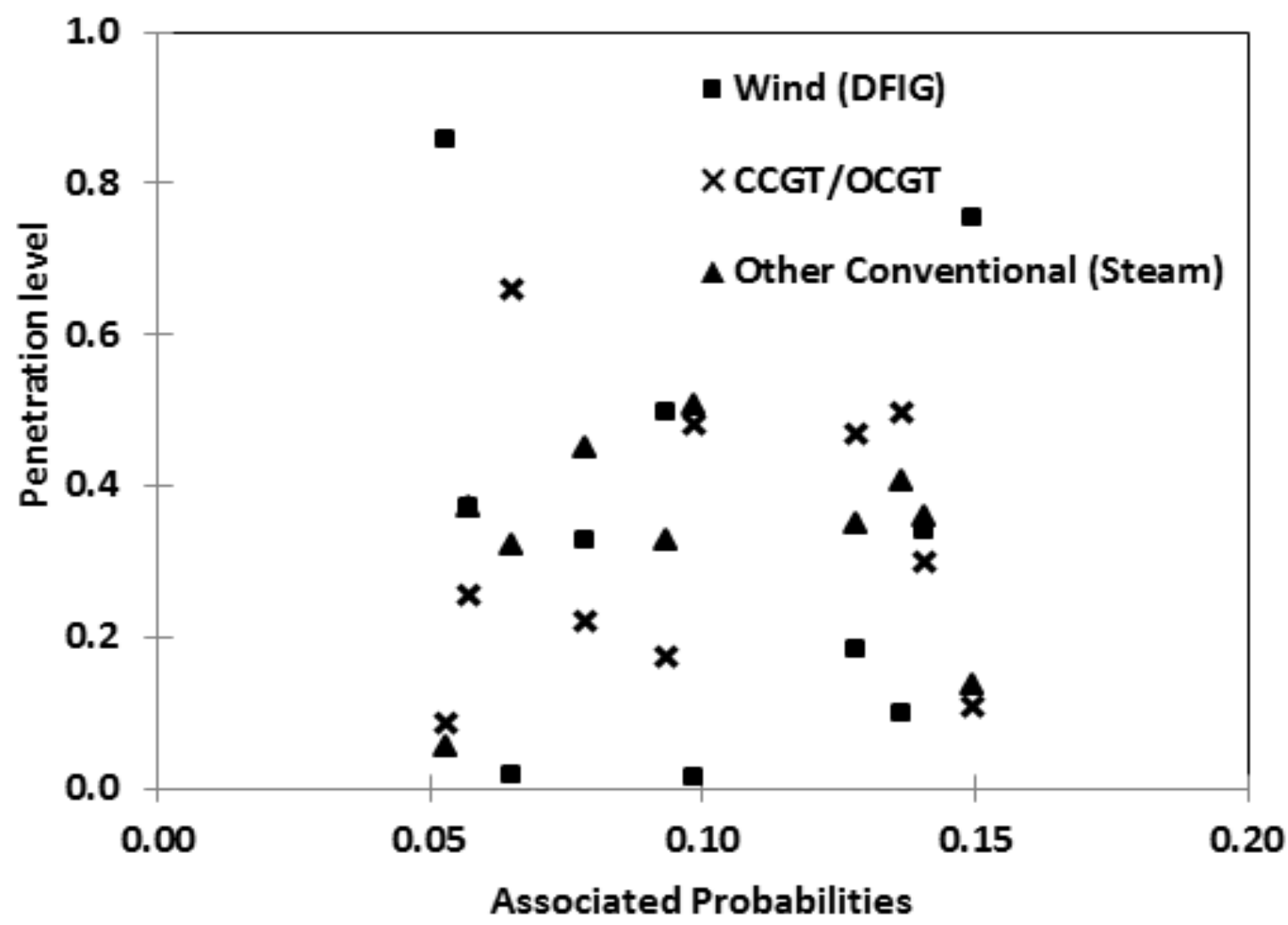

(a)

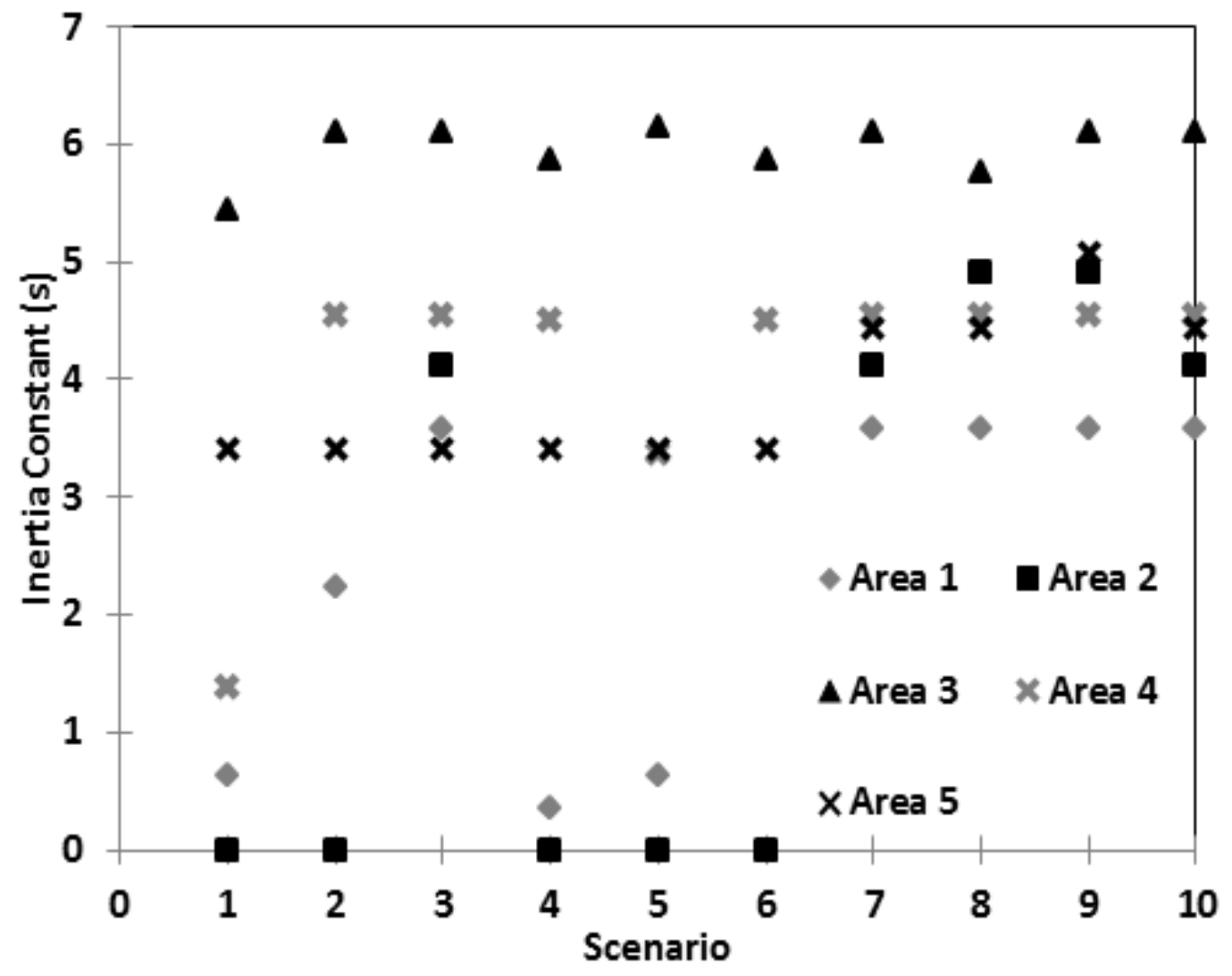

(b)

Figure 12: (a) Wind/ CCGT penetrations vs probability for generation scenarios; (b) Area inertia constant for generation scenarios. 


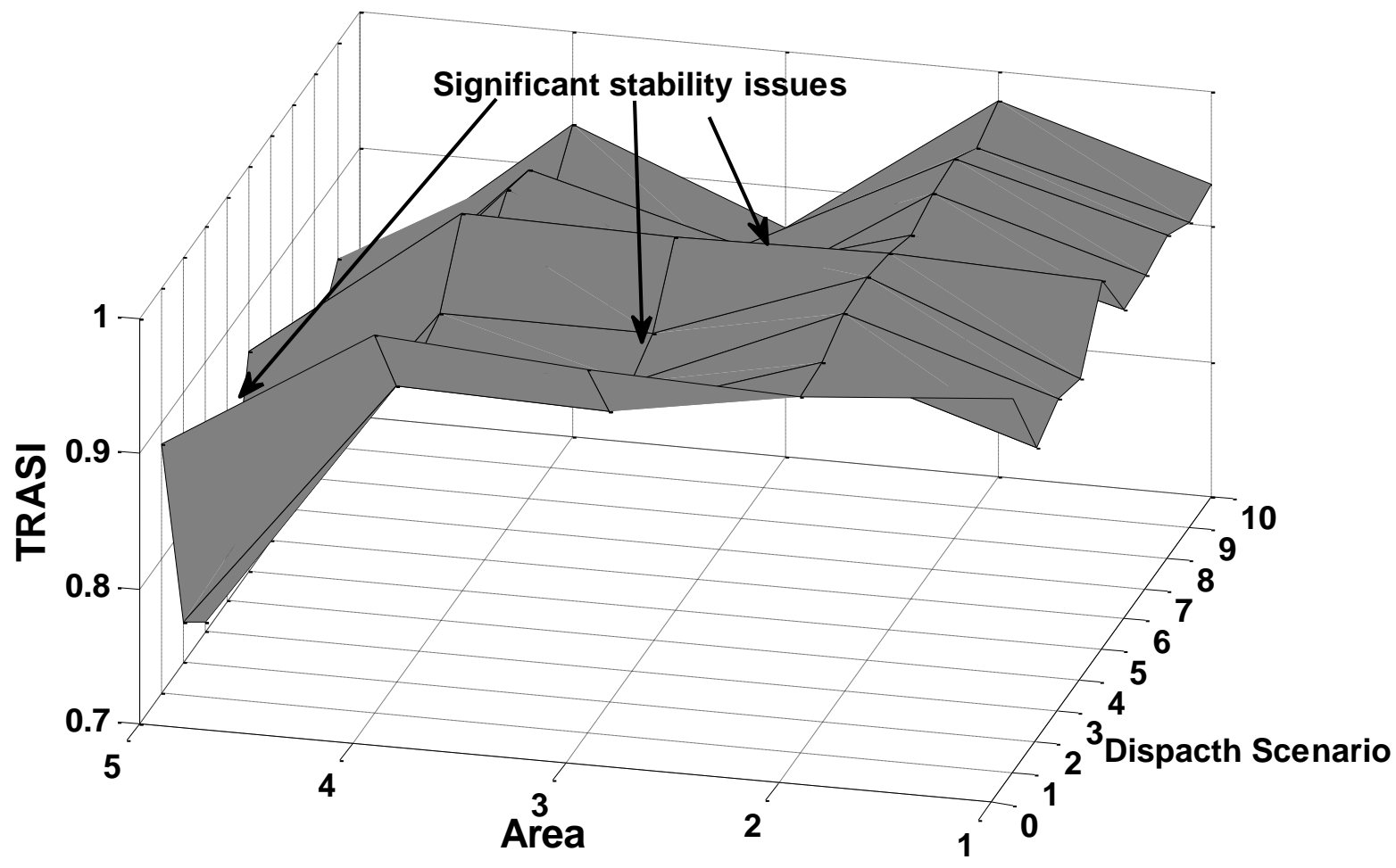

Figure 13: TRASI for dispatch cases.
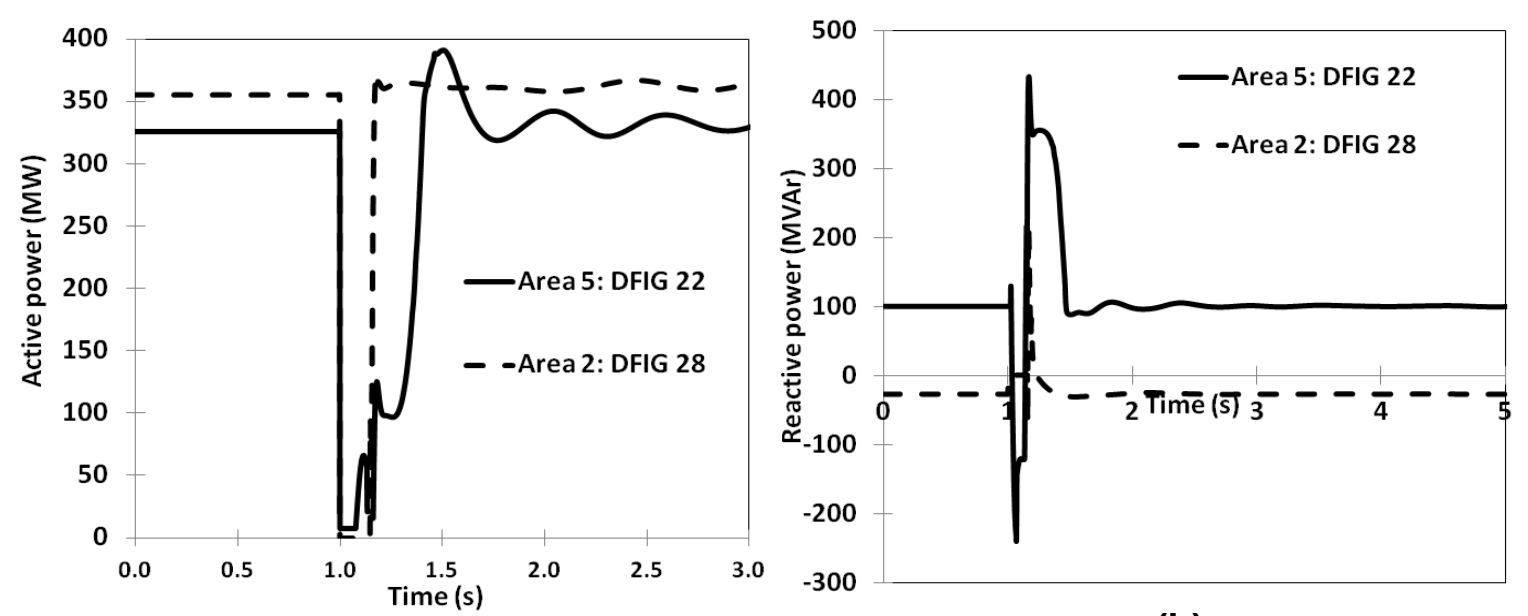

(a)
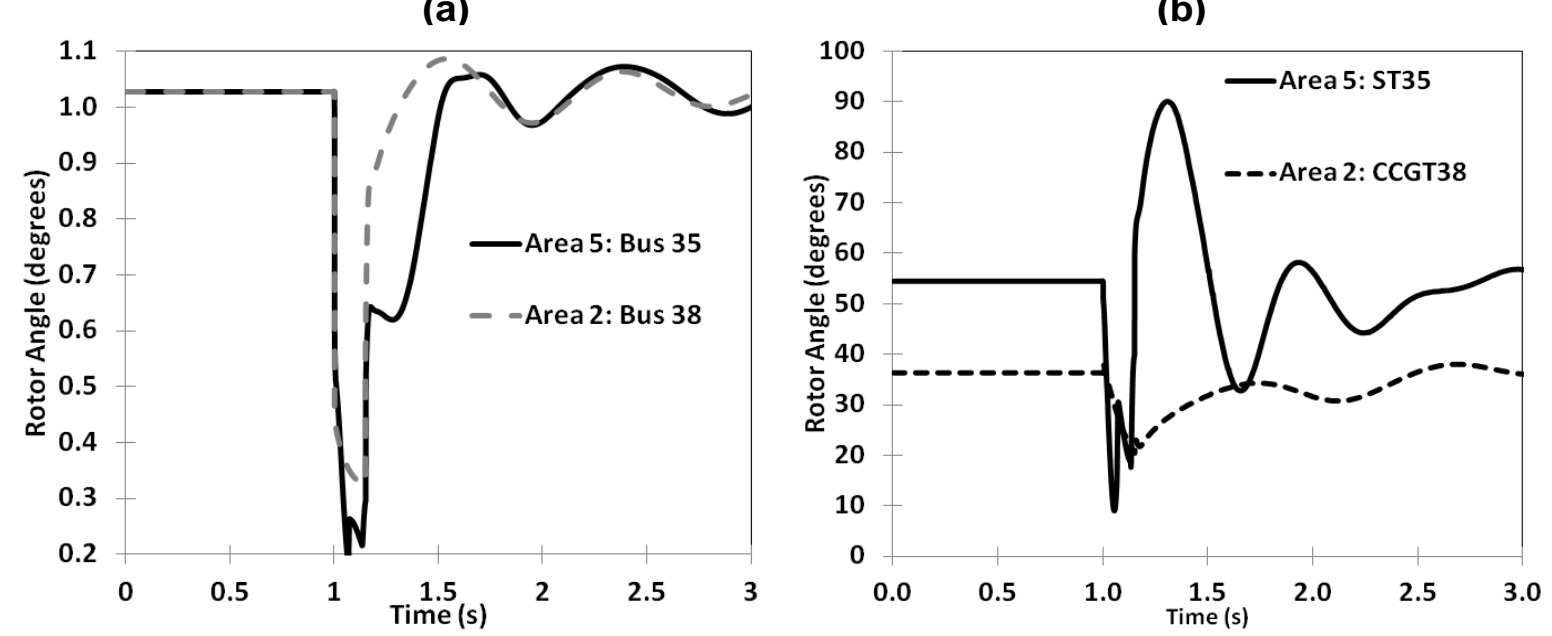

(c)

(d)

Figure 14: Comparison between fault at area 2 and area 5 for dispatch scenario 3. 


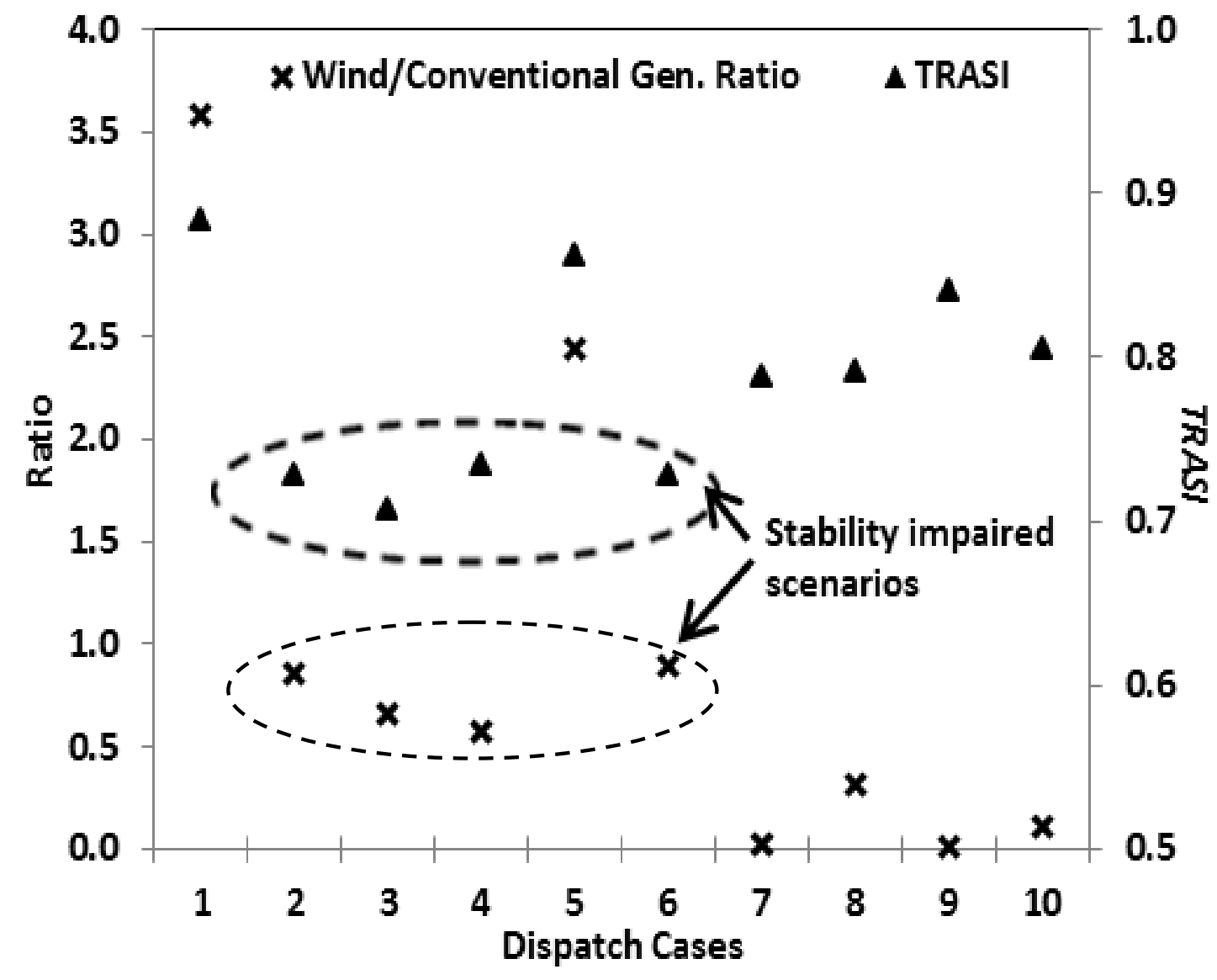

(a)

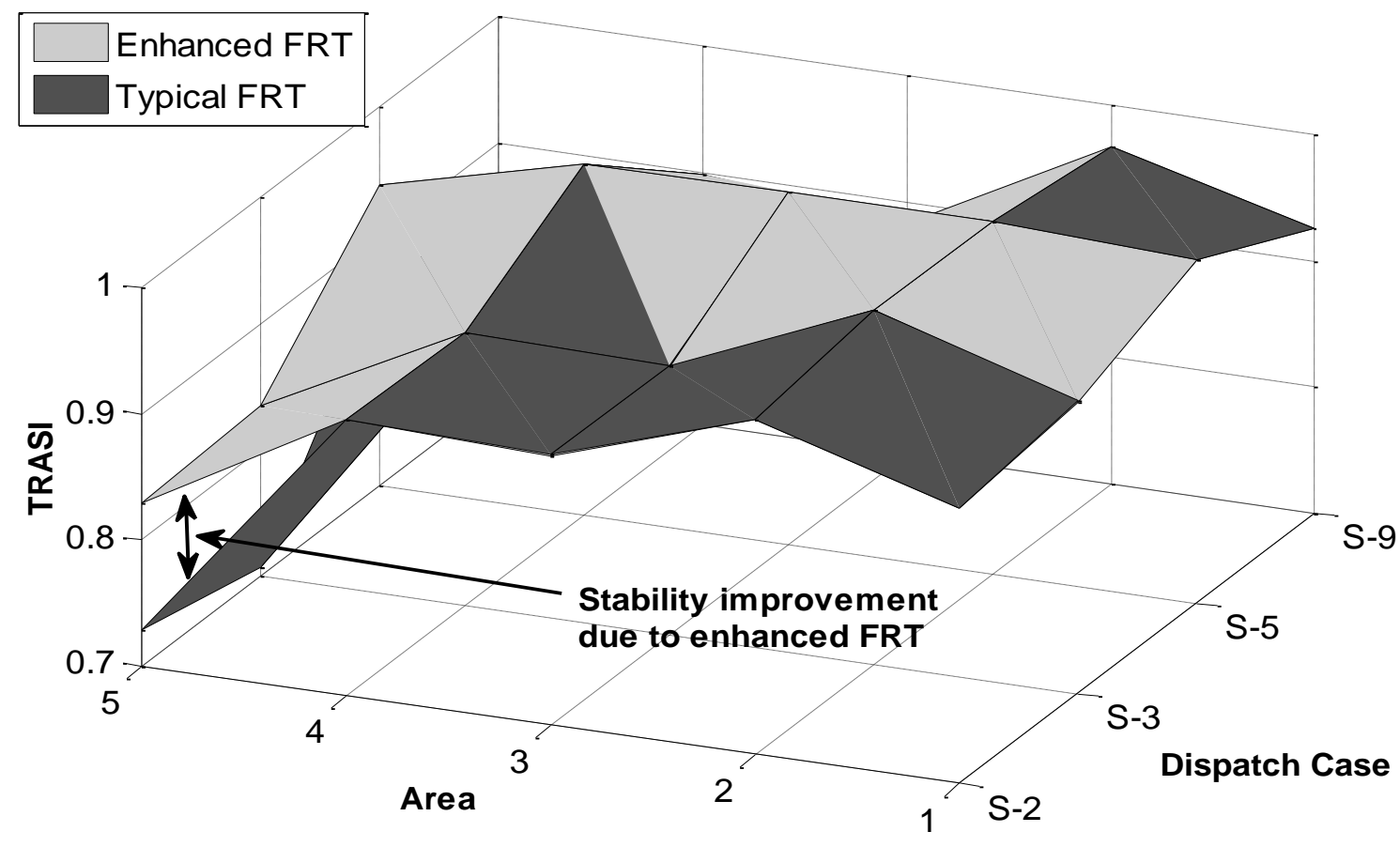

(b)

Figure 15: (a) Variation of wind/conventional generation ratio and TRASI with dispatch scenario for Area 5; (b) Comparison of TRASI for DFIG with enhanced and typical FRT. 


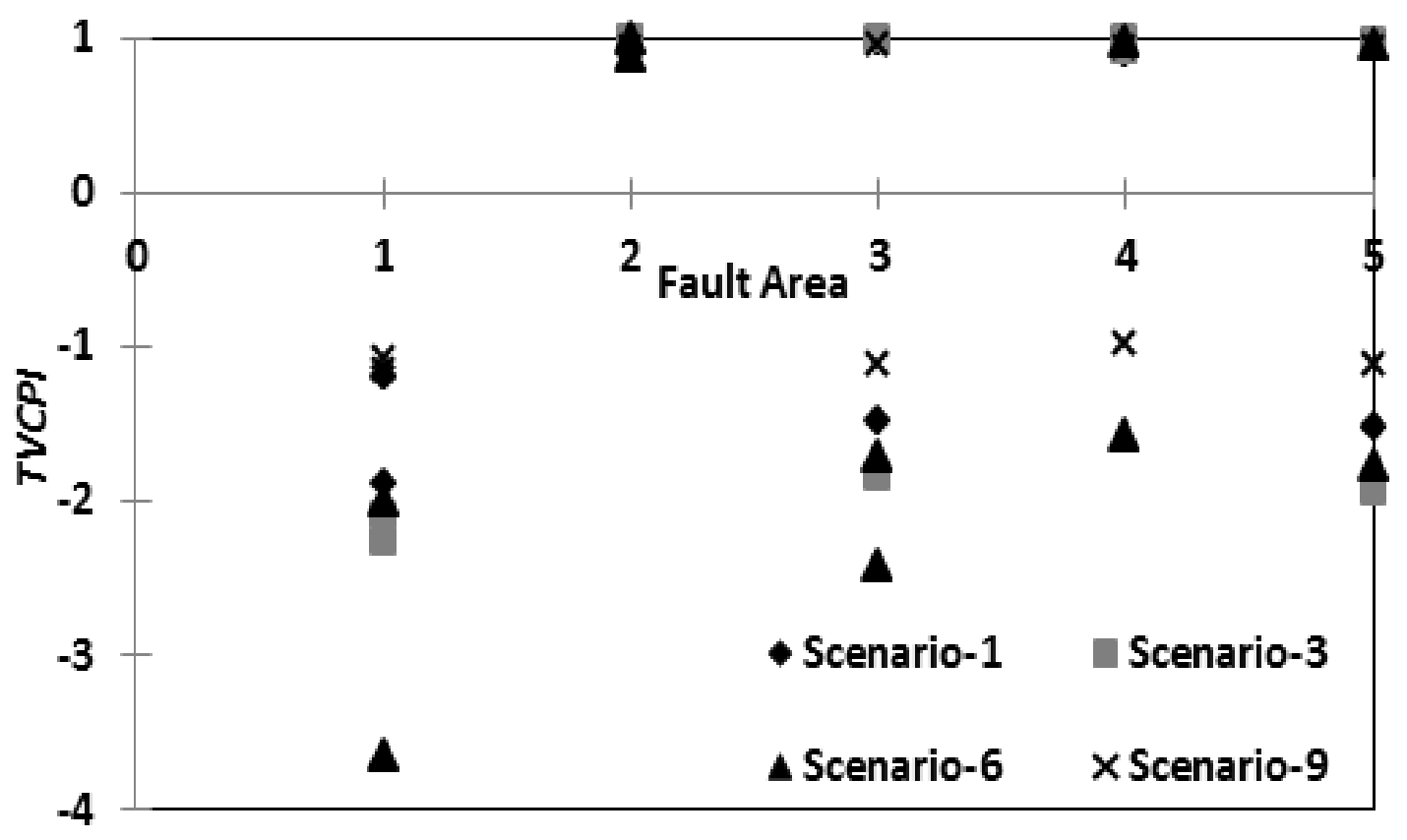

Figure 16: The TVCPI recorded for two wind farm buses in area 1 for dispatch cases.

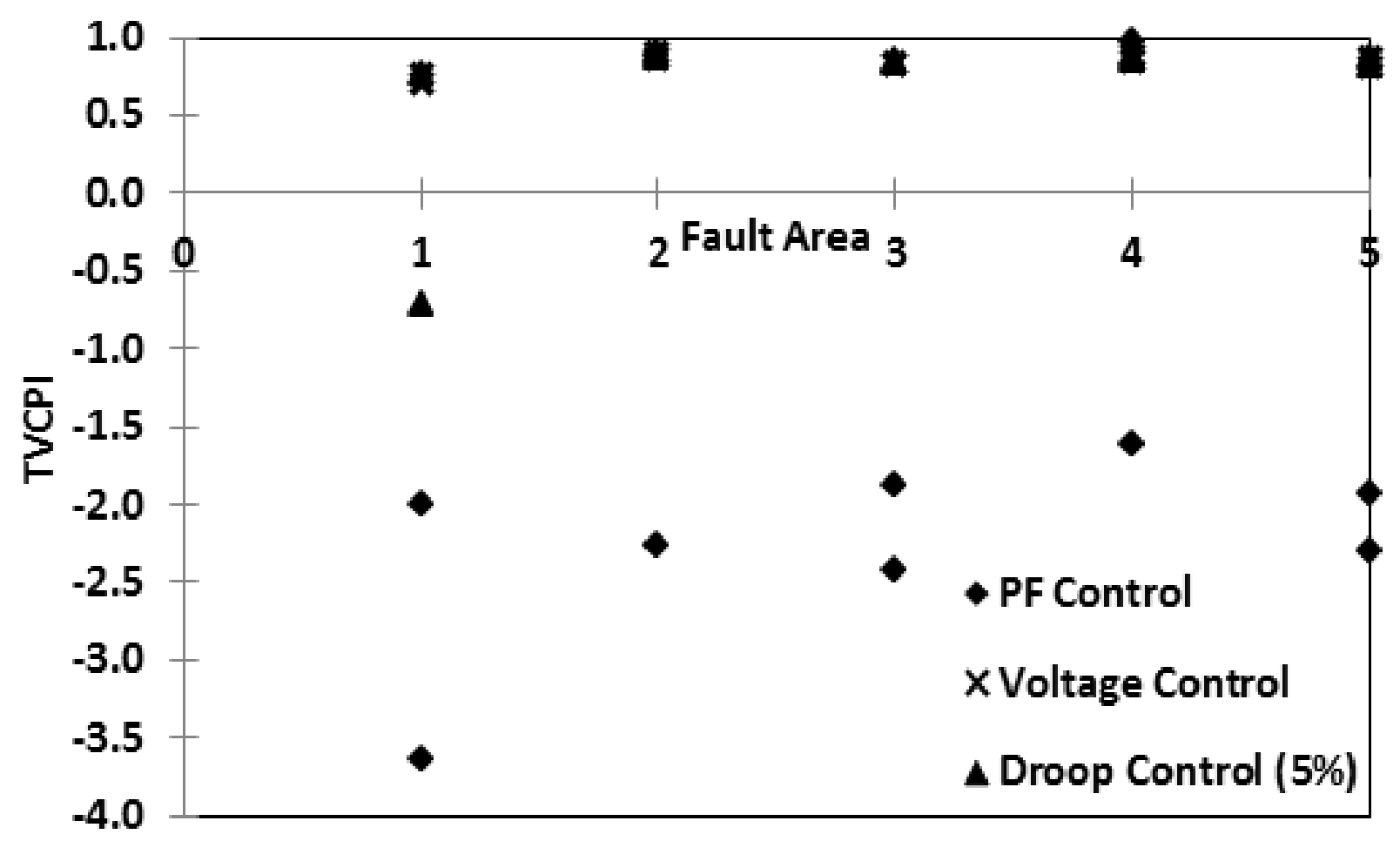

(b)

Figure 17: V-Q curves for bus 16 under different control strategies for the DFIG. 